\title{
Role of the Cannabinoid System in the Limbic System
}

\section{Maryam Azimi $^{1}$, Parastoo Barati Dowom ${ }^{2,3}$, Khadijeh Abdal ${ }^{4}$, Marzieh Darvishi ${ }^{1,2 *}$}

${ }^{1}$ Department of Anatomy, Faculty of Medicine, Ilam University of Medical Sciences, Ilam, Iran

${ }^{2}$ Shefa Neuroscience Research Center, Khatam Alanbia Hospital, Tehran, Iran

${ }^{3}$ Department of Physiology, Faculty of Sciences, Qom Branch, Islamic Azad University, Qom, Iran

${ }^{4}$ Department of Oral and Maxillofacial Pathology, Dental Faculty, Ilam University of Medical Sciences, Ilam, Iran

Article Info:

Received: 3 Jan 2017

Revised: 13 May 2017

Accepted: 3 Oct 2017

\section{A BSTRACT}

Introduction: The limbic system plays an important role in neural mechanisms related to emotion and memory. Hallucinogenic drugs are a factor affecting the functioning of this system and interfering with its nervous system regulation. Recent studies on adolescent users of hallucinogenic drugs, such as marijuana, have shown some degree of behavioral and emotional disorders. Cannabinoids, compounds forming marijuana, acting via its receptors throughout the brain. Conclusion: These ligands bind to their receptors in parts of the limbic system (the amygdala, prefrontal cortex, hippocampus, thalamus and hypothalamus) and lead to changes in the expression of neurotransmitters and neural pathways in the brain. These alterations influence emotional behavior.

*Corresponding Author: Marzieh Darvishi

E-mail: Marzidarvish@yahoo.com 


\title{
نقش كانابينوئيد سيستم در سيستم ليمبيك
}

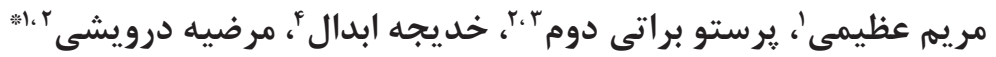 \\ اكَروه آناتومى، دانشكده يزشكى، دانشعاه علوم يزشكى ايلام، ايلام، ايران

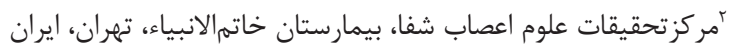

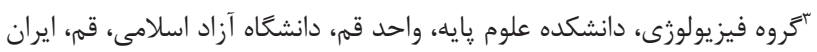

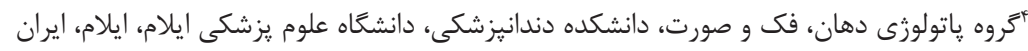

\section{اطلاعات مقاله:}

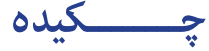

مقدمه: سيستم ليمبيك نقش مهمى در مكانيسمهاى عصبى وابسته به احساسات و حافظه بازى مى كند.

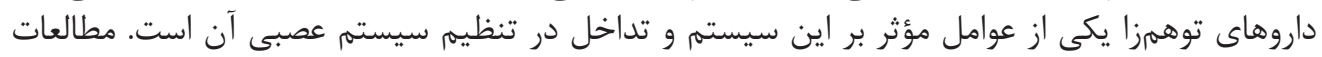

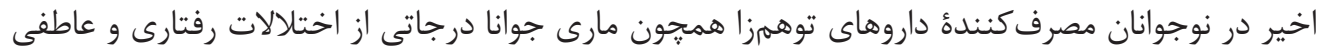

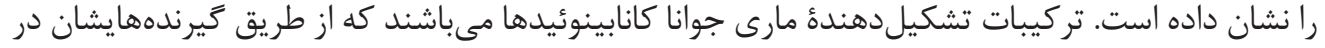

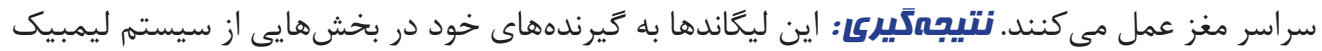

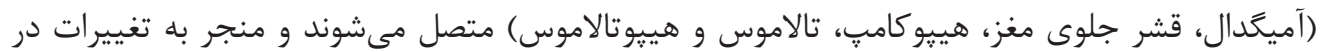

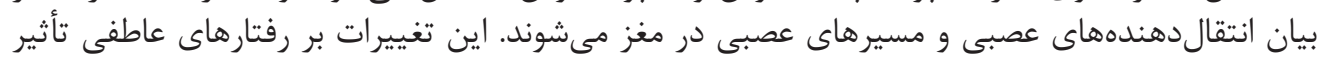
مى كذارد.

\footnotetext{
كليد وازمها:

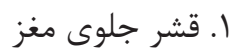
r.

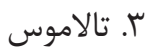

$$
\text { * نويسنده مسئول: مرضيه درويشى : }
$$
آدرس الكترونيكى: Marzidarvish@yahoo.com 
مهمهرين تركيبات كياهى كه تحت عنوان كانابينوئيد شناخته

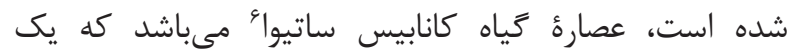

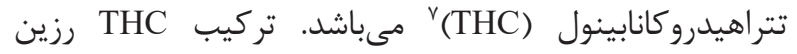

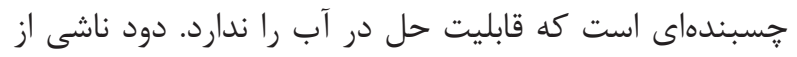

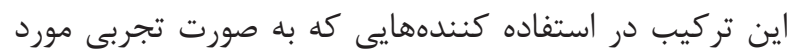

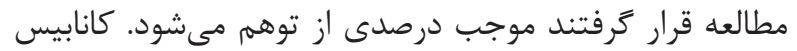

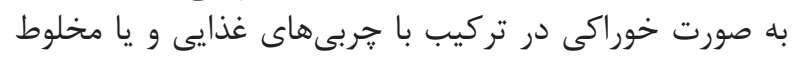

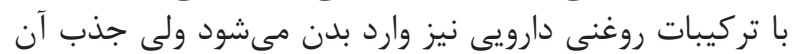

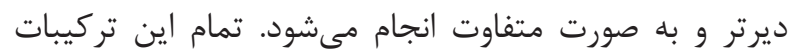

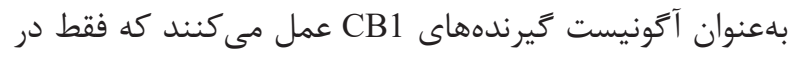

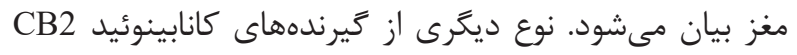

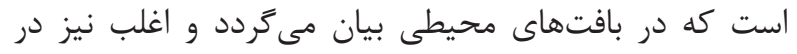

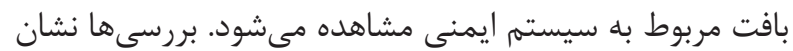

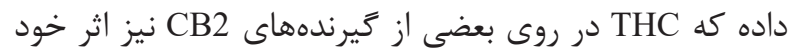

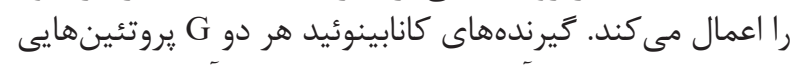

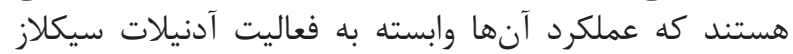

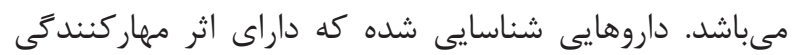

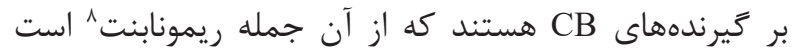

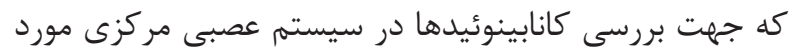

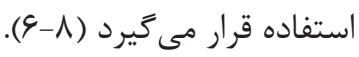

\section{r- كانابينوئيدهاى اندوزنوس}

بعد از بررسىهايى كه در زمينأ كيرندهائ كانابيناينوئيد انجام

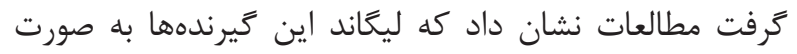

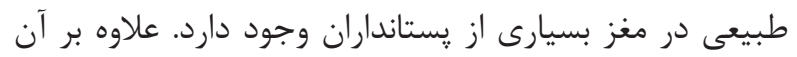

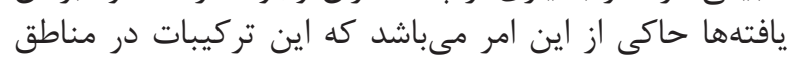

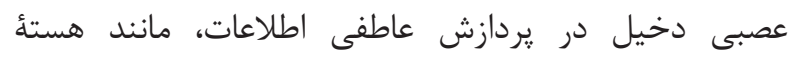

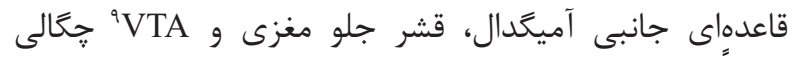

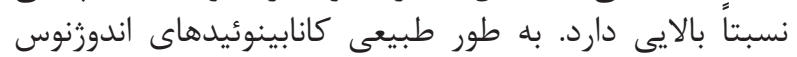

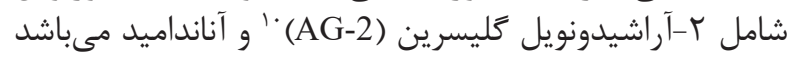

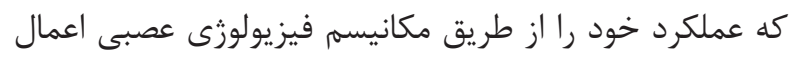

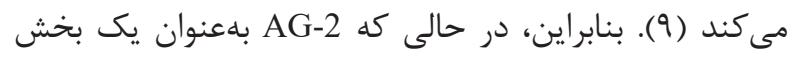

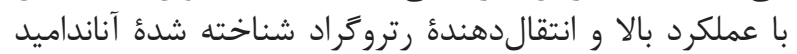

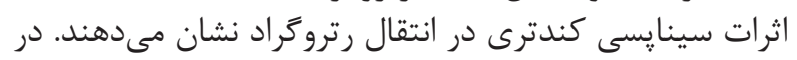

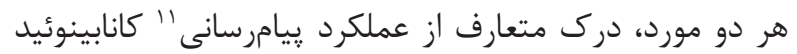

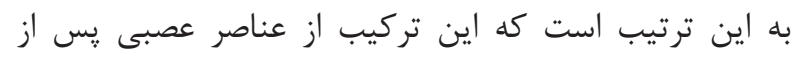

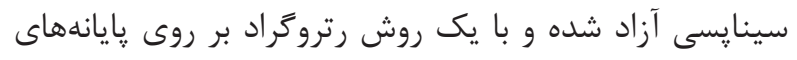

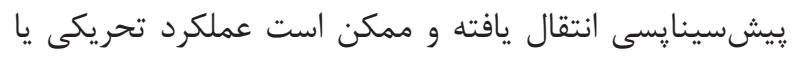

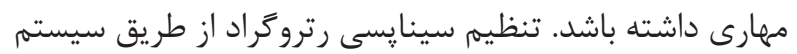

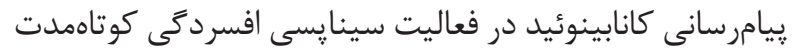

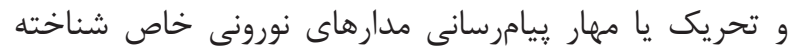

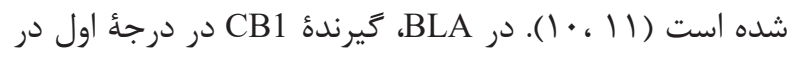

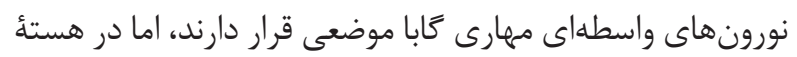

${ }^{1}$ Neurotransmitter

${ }^{2}$ Calcitonin gene related peptide

${ }^{3}$ Prefrontal cortex

${ }^{4}$ Basolateral nucleus amygdala

${ }^{5}$ Dopamine

${ }^{6}$ Cannabis sativa
تحقيقات اخير نشان داده كه استفاده از مارى جوانا در انسان

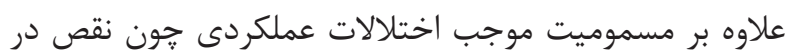

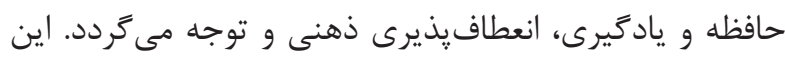

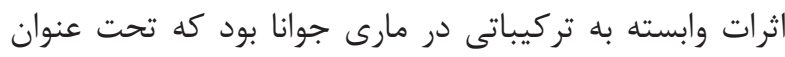

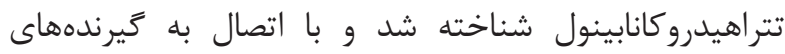

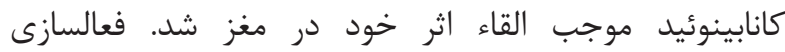

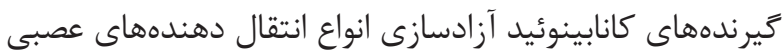

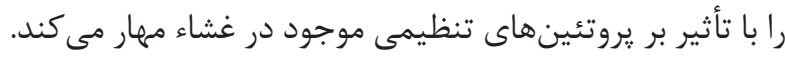

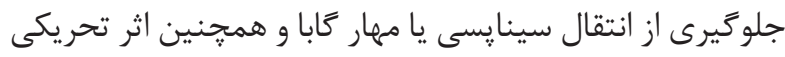

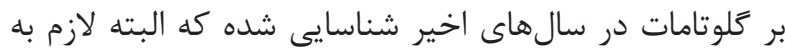
تحقيق در اين موارد مى باشد

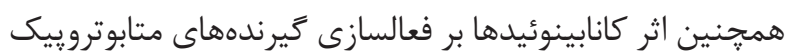

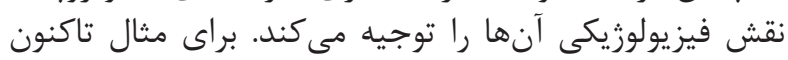

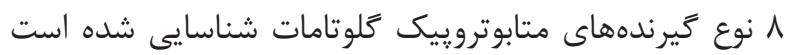

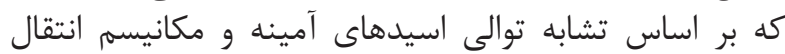

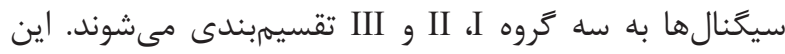

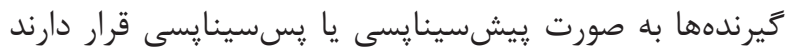

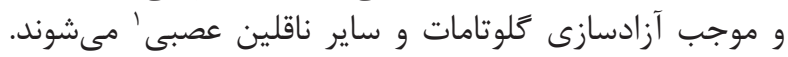

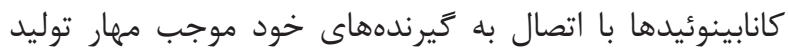

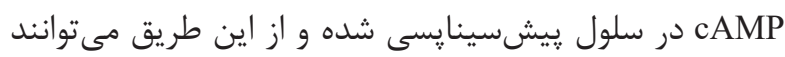

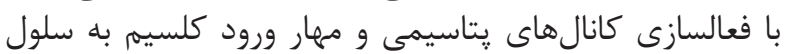

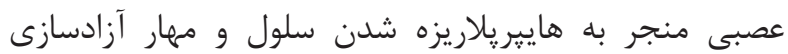

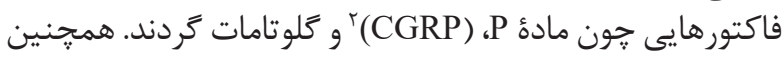

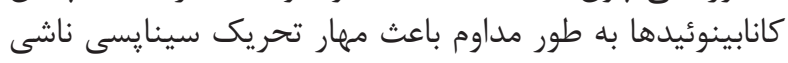
از تقويت طولانىمدت مىشوند (r- (1).

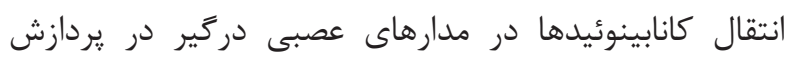

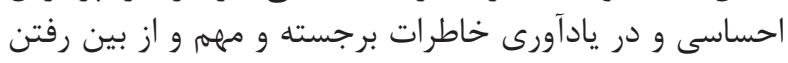

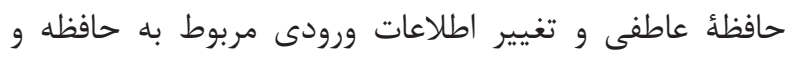

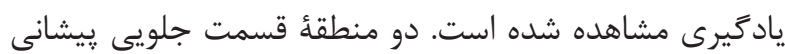

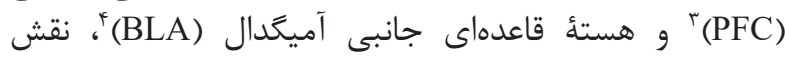

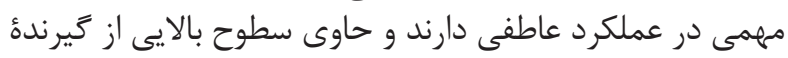

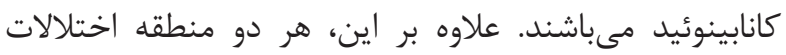

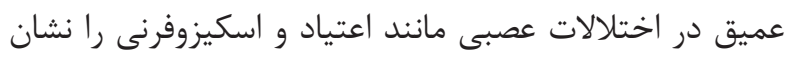

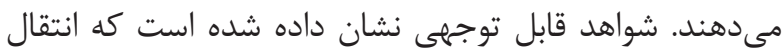

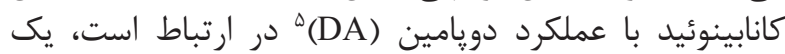

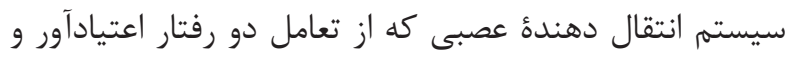

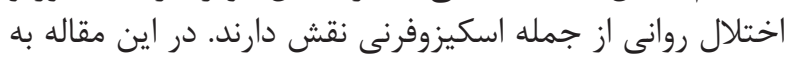

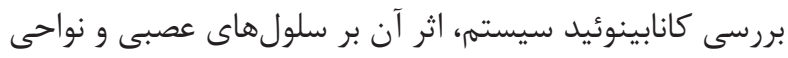

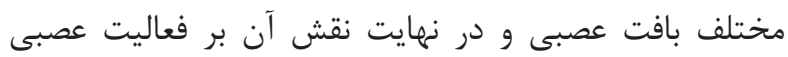

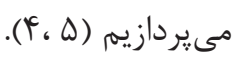

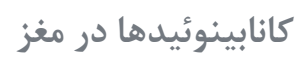

\footnotetext{
${ }^{7}$ Tetrahydrocannabinol

${ }^{8}$ Rimonabant

${ }^{9}$ Ventral tegmental area

${ }^{10}$ 2-arachidonoylglycerol

${ }^{11}$ Signaling
} 


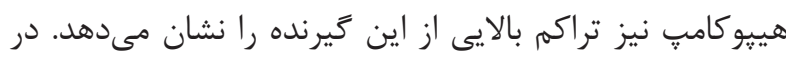

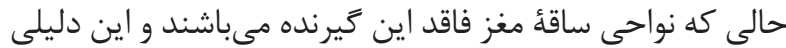

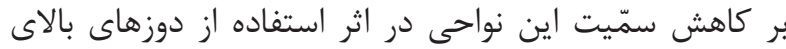

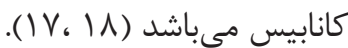

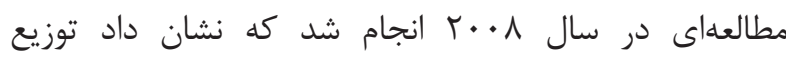

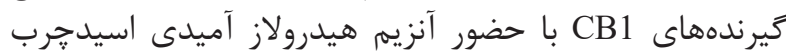

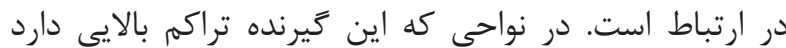

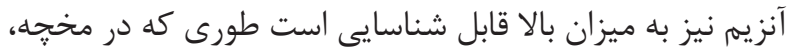

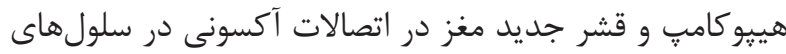

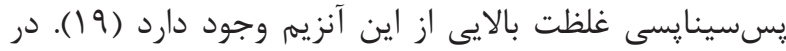

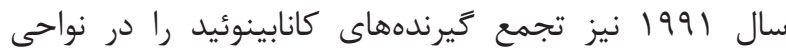

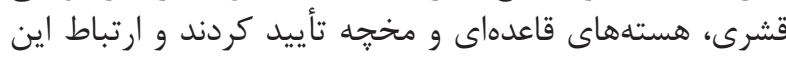

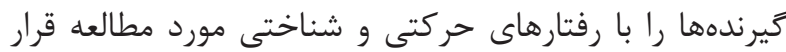

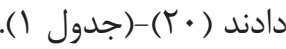

$$
\text { اثر كانابينوئيد بر سلول عصبى }
$$

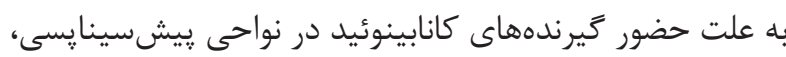

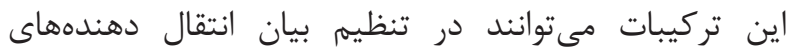

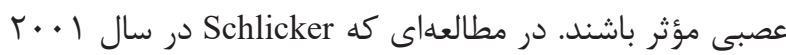

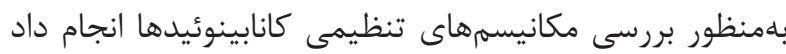

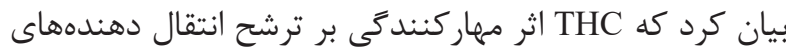

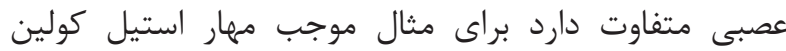

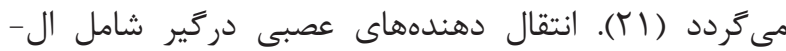

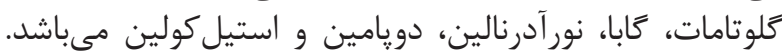

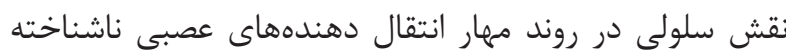

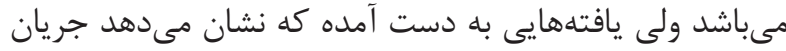

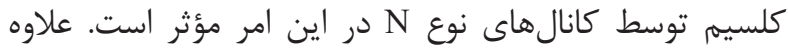

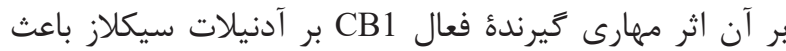
كاهش فسفر يلاسيون نوع A كانال هاى يتاسيمى به به وسيلة آنزيم

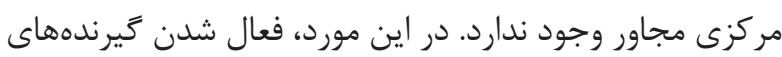

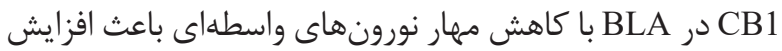

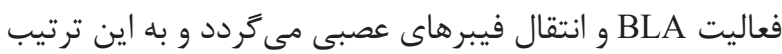

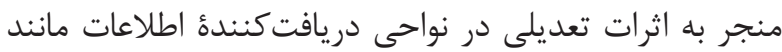

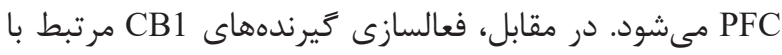

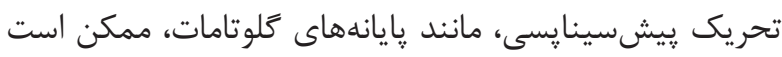

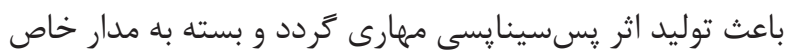

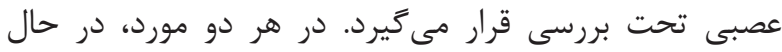

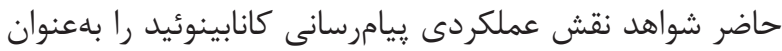

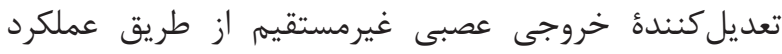

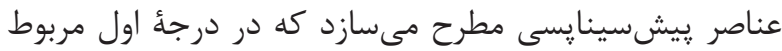

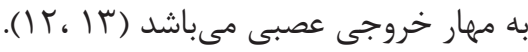

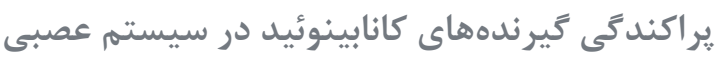

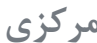

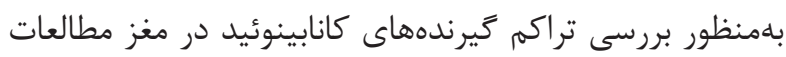

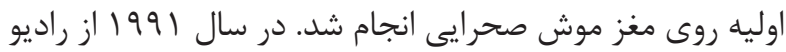

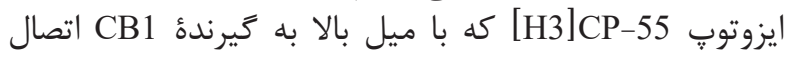

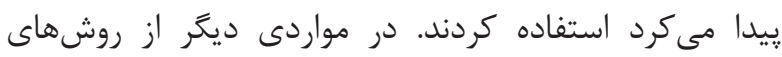

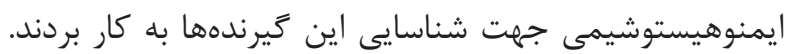

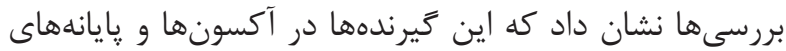

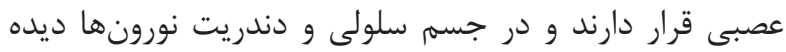

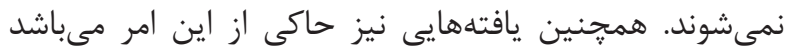

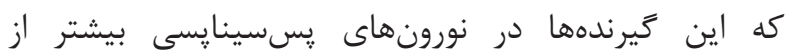

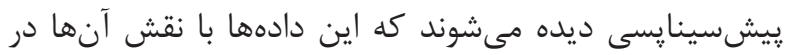

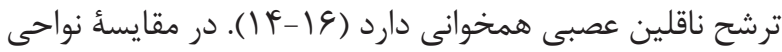

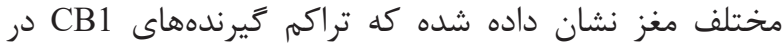

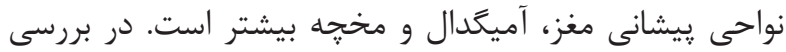

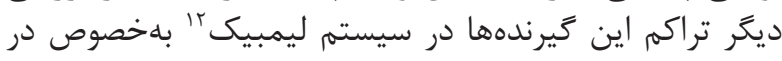

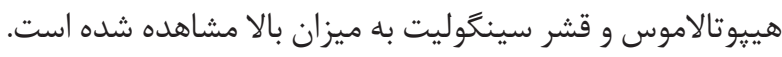

جدول ا- يراكندگى گيرندهاى كانابينوئيد در سيستم عصبى مركزى.

\begin{tabular}{|c|c|c|}
\hline زير تروهoا & كيرندة كانابينوئيد & 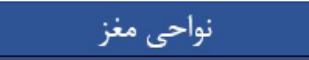 \\
\hline 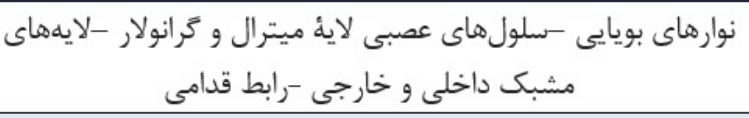 & $\mathrm{CB} 1$ & 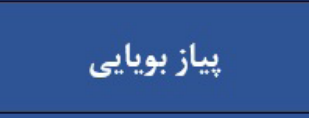 \\
\hline قشر انتورينال (قشر بويايى اوليه) -قشر بويايى ثانويه & CB1 & قشر بويايى \\
\hline در لايههاى اول تا ششم قشر و در لوبهاى فرونتال - بريتال - & CB1 & مغز قدامى (قشر جديد) \\
\hline لوب فرونتال و يرهفرونتال & CB1 & مغز قدامى (برهفرونتال) \\
\hline نواحى CA1، سابيكولوم و CA3 & CB1 & هيبوكامب \\
\hline- & CB1 & مخهجه \\
\hline در تمام هستههاى آميكدال به صورت اشعهايى يراكنده ديده & CB1 & آميكدال \\
\hline در تمام هستههاى تالاموس به صورت يراكنده ديده مىشود & CB1 & تالاموس \\
\hline در تمام هستههاى هييوتالاموس به صورت يراكنده ديده مىشود & CB1 & 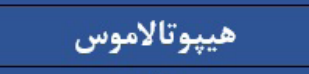 \\
\hline 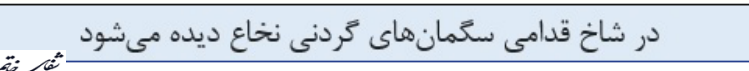 & CB1 & نخاع \\
\hline
\end{tabular}

${ }^{12}$ Limbic system 


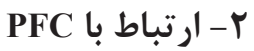

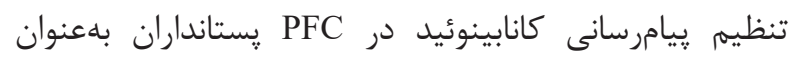

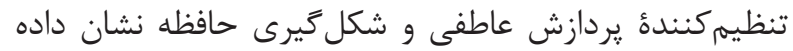

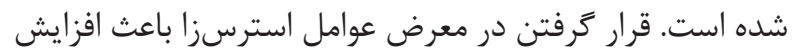

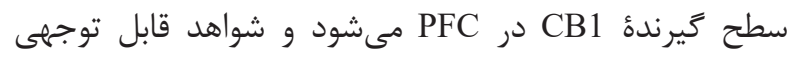

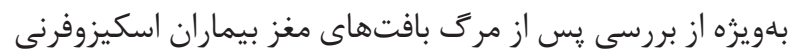

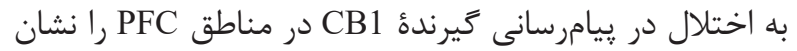

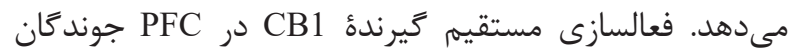

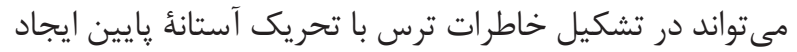

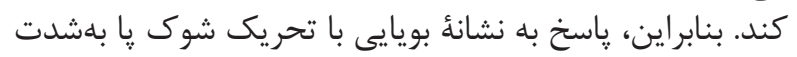

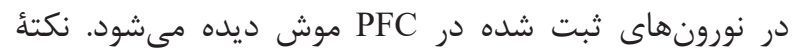

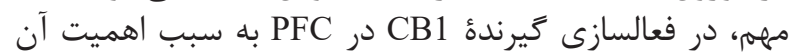

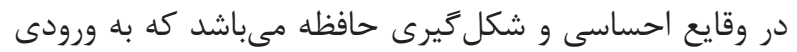

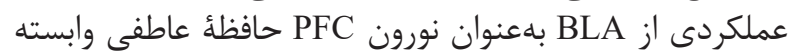

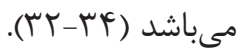

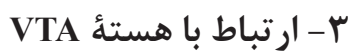

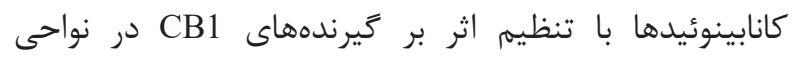

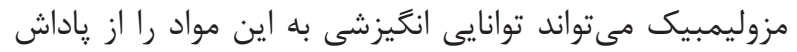

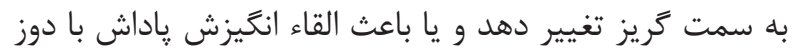

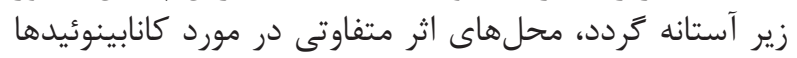

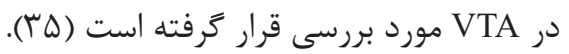

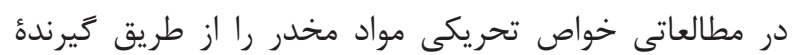

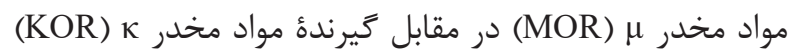

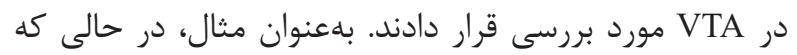

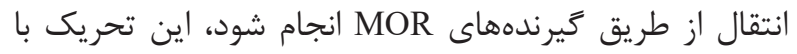

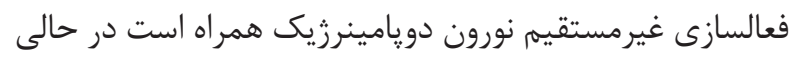
كه اثر از طريق كيرنده

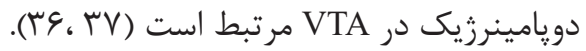

يافته نشان داده توانايى فعالسازى كيرنده

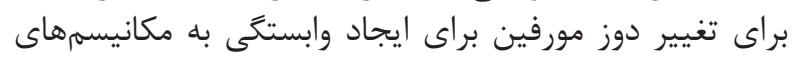

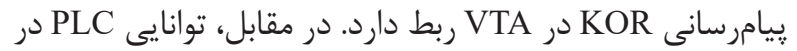

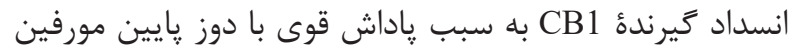

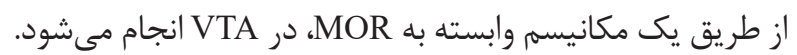

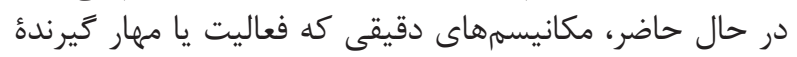

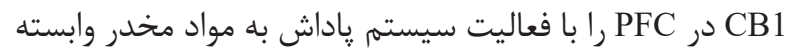

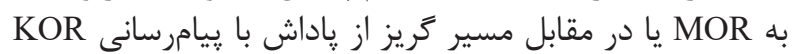

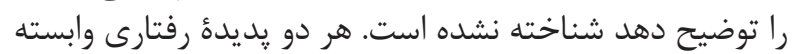

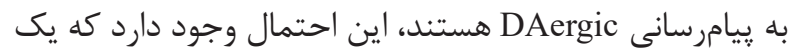

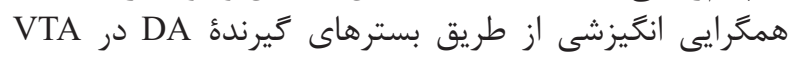

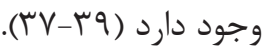

بررسى هاى محققين نشان داد كه KOR در VTA

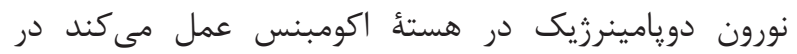

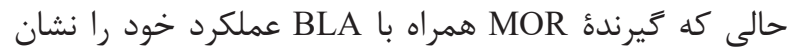

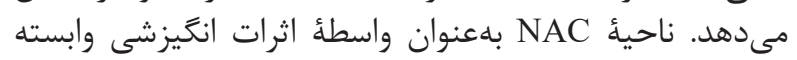

يروتئين كيناز A وابسته به cAMP مىشود (T T).

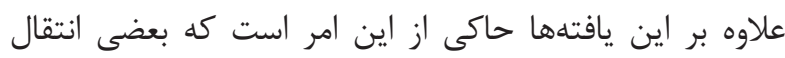

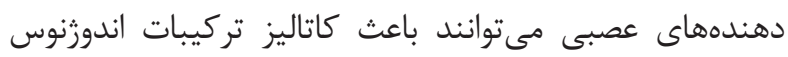

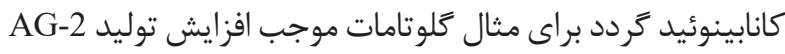

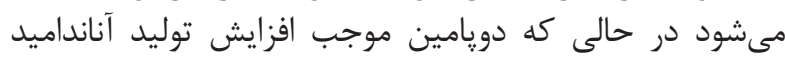

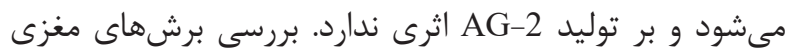

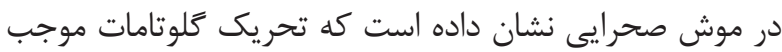

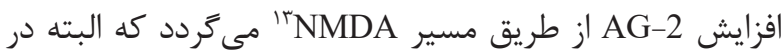

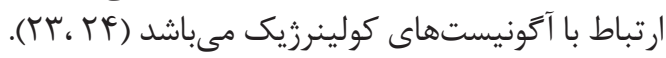

ارتباط كانابينوئيدها با سيستم عصبى مركزى (سيستم

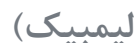

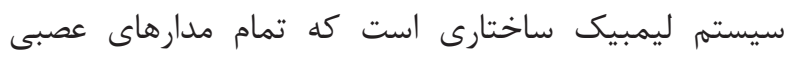

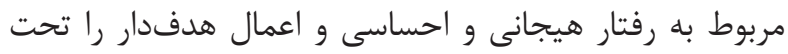

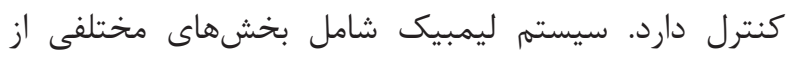

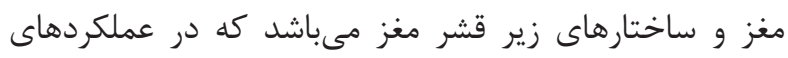

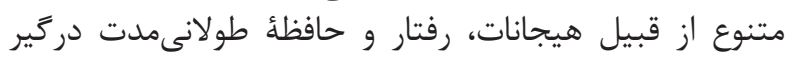

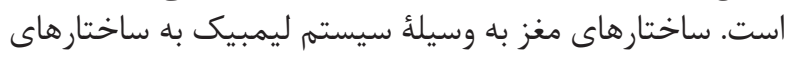

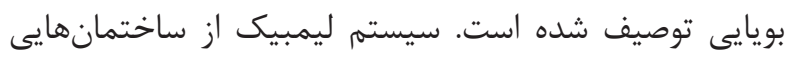

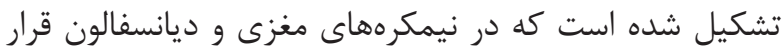

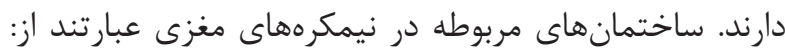

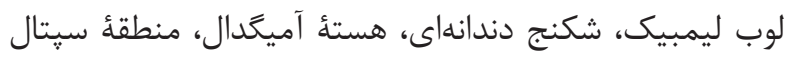

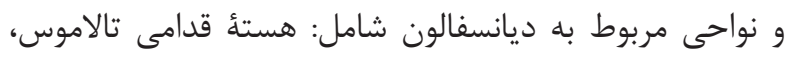

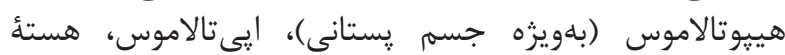

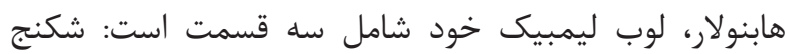

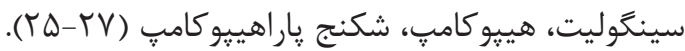

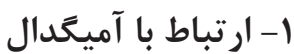

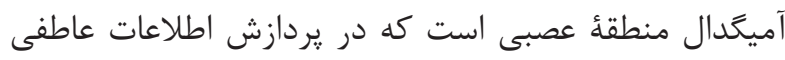

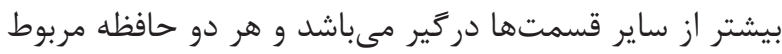

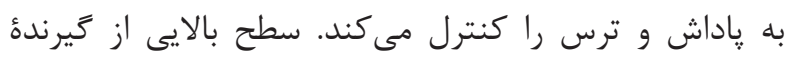

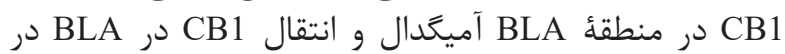

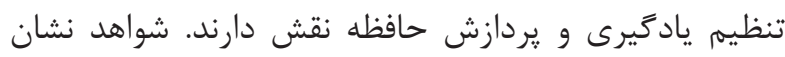

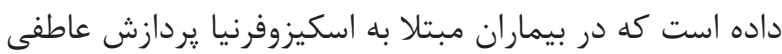

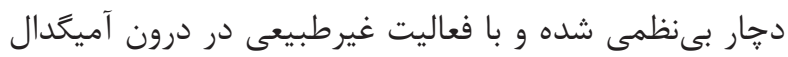

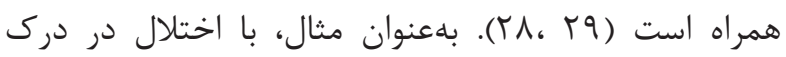

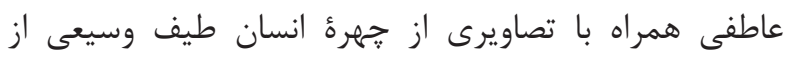

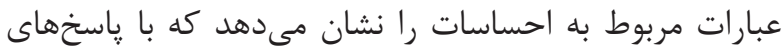

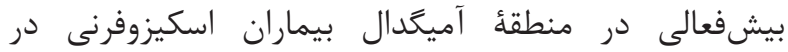

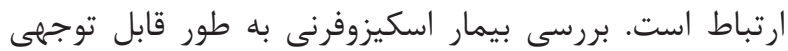

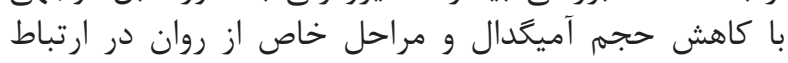

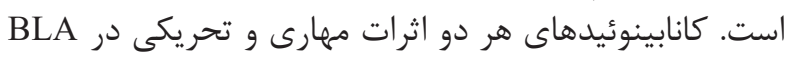

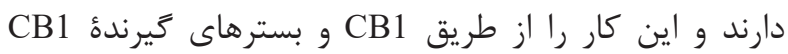

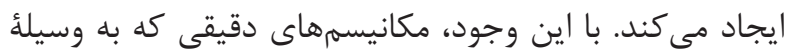

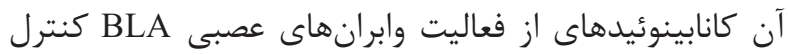

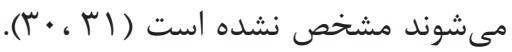


در مطالعات انجام شده نشان داده شد كه گيرندههاى كانابينوئيد

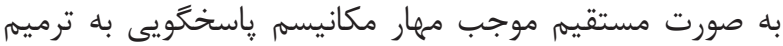

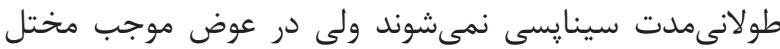

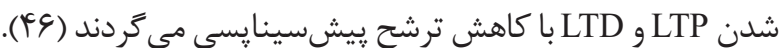

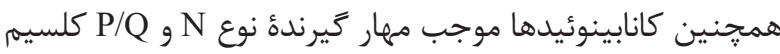

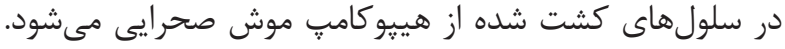

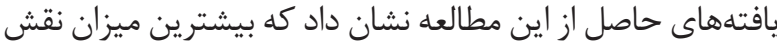

كانابينوئيد بر تنظيم انتقال ناقلين عصبى مى إشاشد (FV) نقش اصلى ييامرسانى هييو كامٍ در استفاده از كانابينوئيدهايى

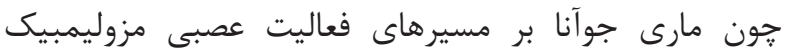
نشان داده عدم تنظيم كيرندهارئاى كانابينوئيد در مسير مسير ونترال

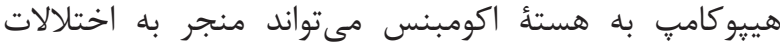

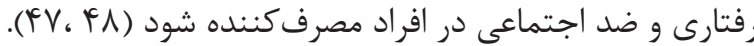
كانابينوئيد - يردازش عاطفه و يادكيرى (ارتباط متقابل با

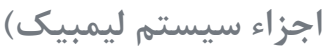

به طور كلى بررسى هاى مختلف نشان داده كه نواحى وابسته به

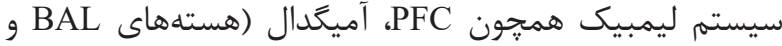

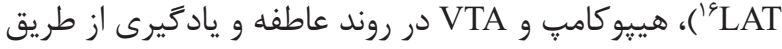

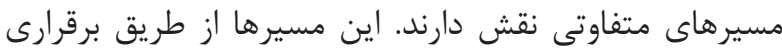

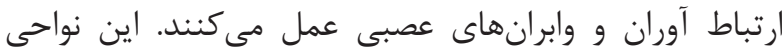

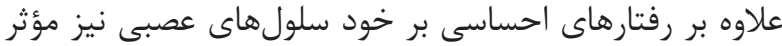

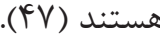

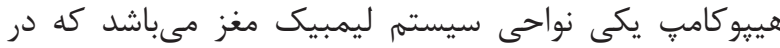

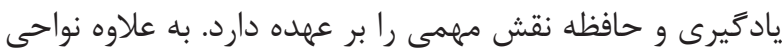
CA2 و ورودى CA1

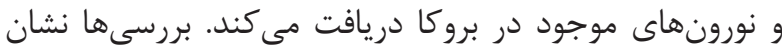

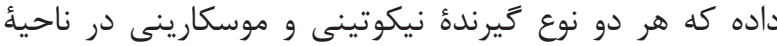

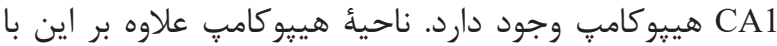

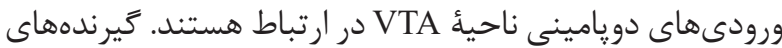

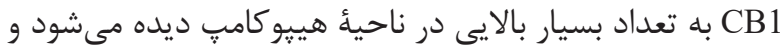

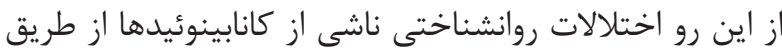

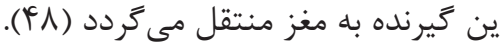

هستهاى BAL، فيبرهايى تحريكى كلوتامات را از PFC

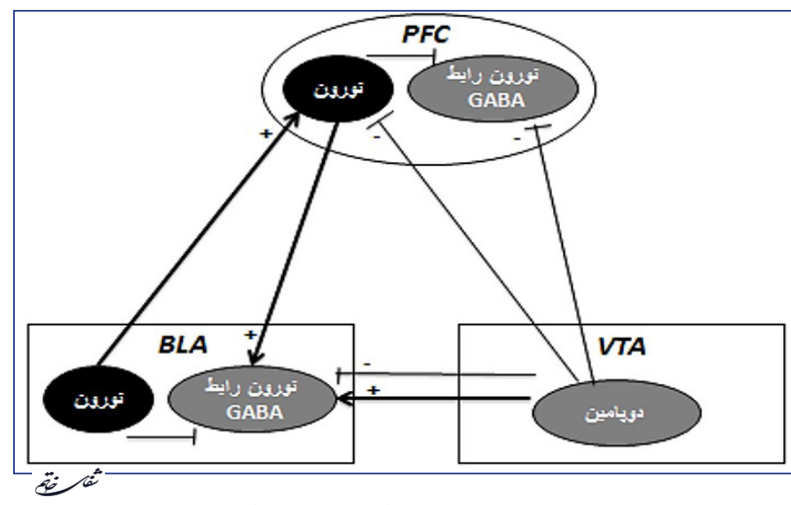

تصوير ا- تصوير شماتيك از عملكرد و ارتباط آناتوميك PFC، آميكدال (هستهاى BAL) و
به دويامينرزيك است، مانند عواملى كه در ارتباط با نيكوتين

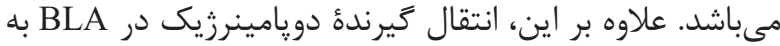

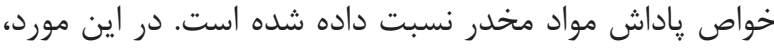

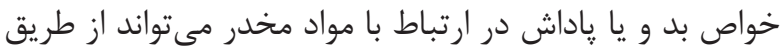

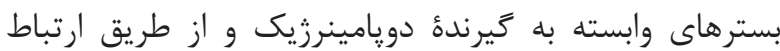

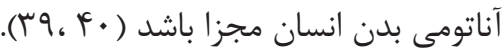

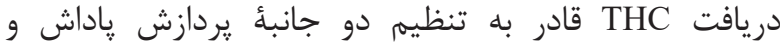

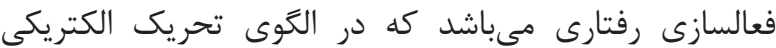

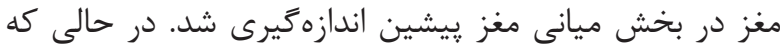

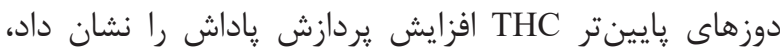

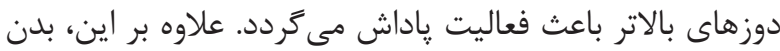

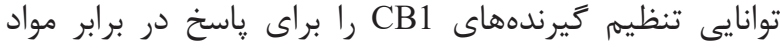

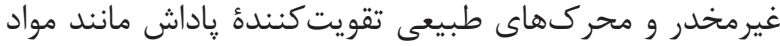
غذايى را دارند. بهعنوان مثال مهار انتقال

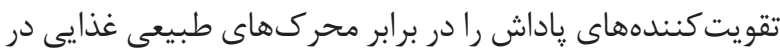

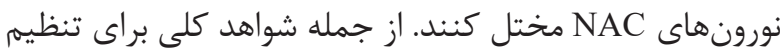

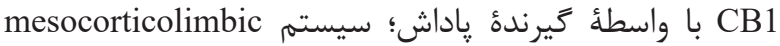

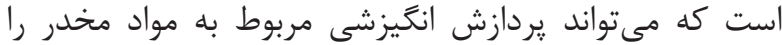

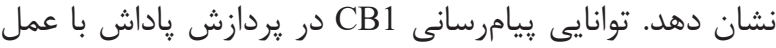

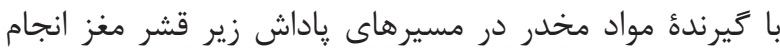

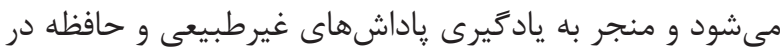

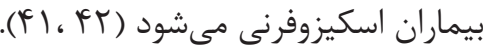

F - ارتباط با هييو كامب

بررسى اثر كانابينوئيد در موش صحرايى نشان داده كه مانه

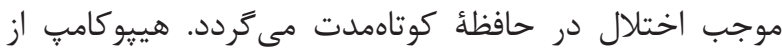

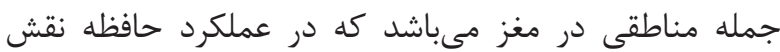

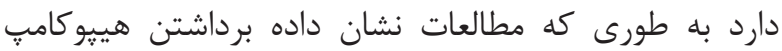

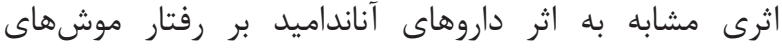

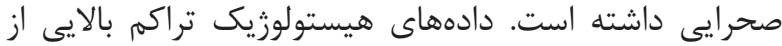

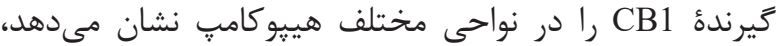

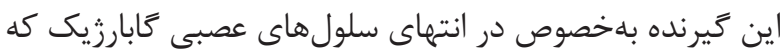

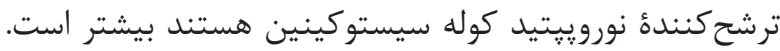

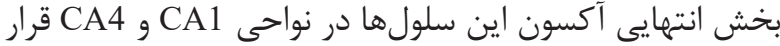

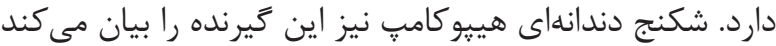

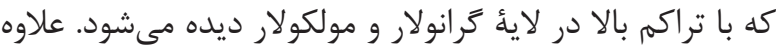

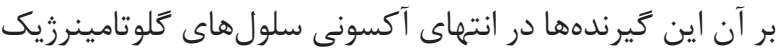

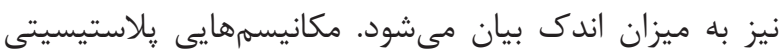

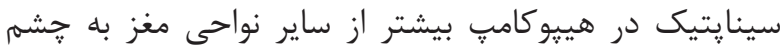

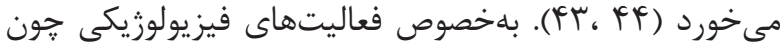

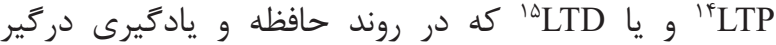

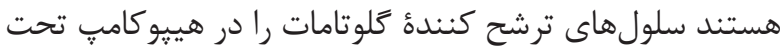

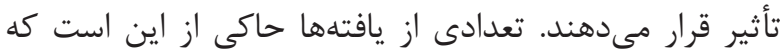

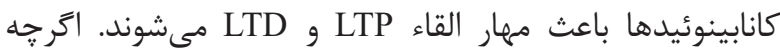

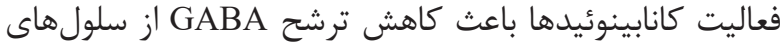

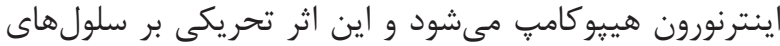

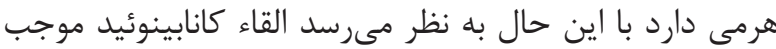

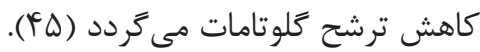

${ }^{14}$ Long-term potentiation

${ }^{15}$ Long-term depression

${ }^{16}$ Lateral nuclei 


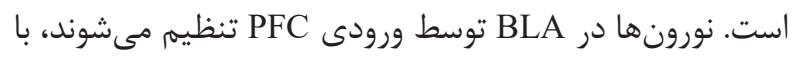

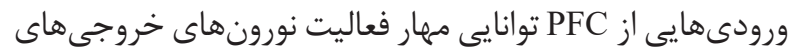

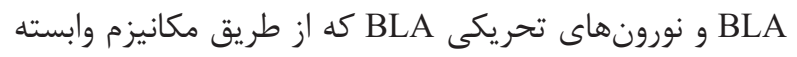

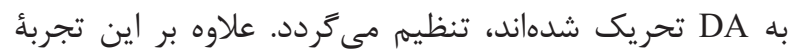

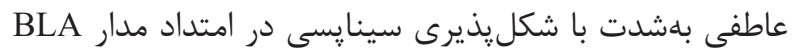

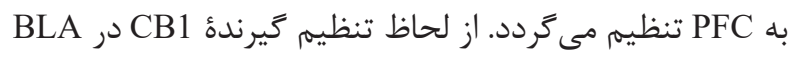

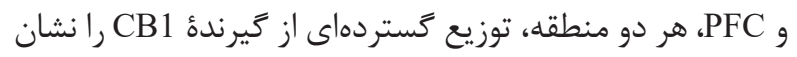

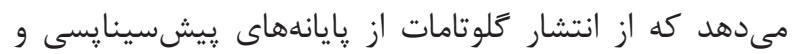

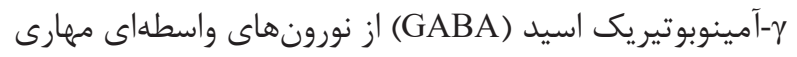

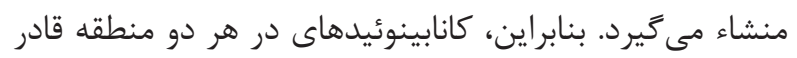

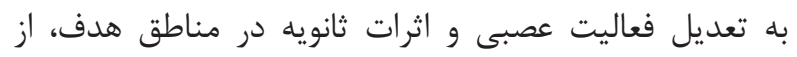

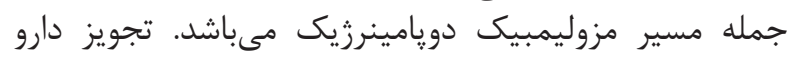

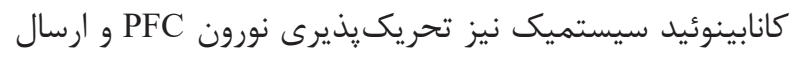

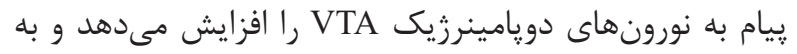

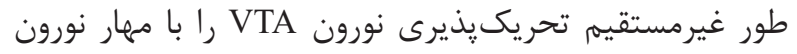

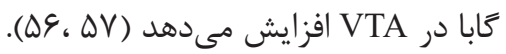

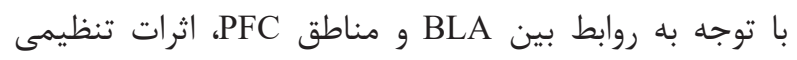

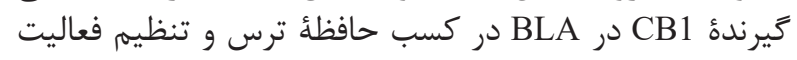

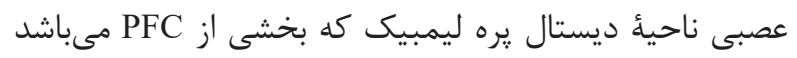

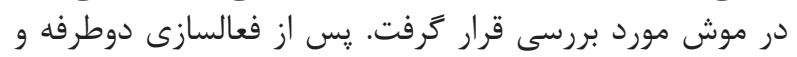

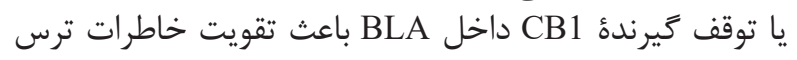

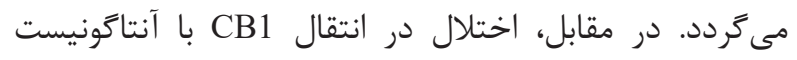

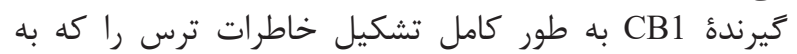

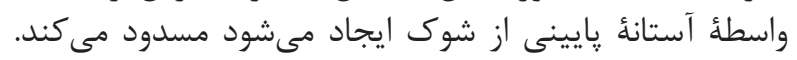

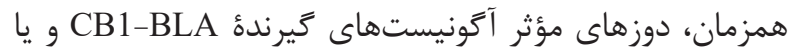

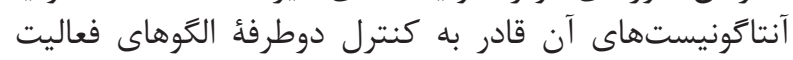

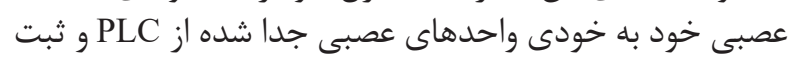

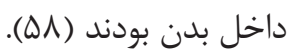

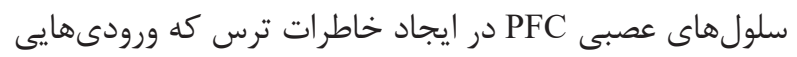

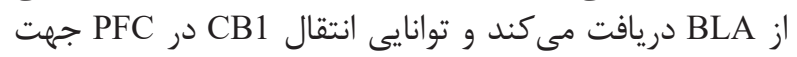

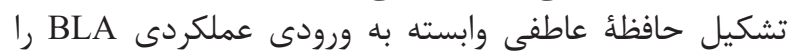

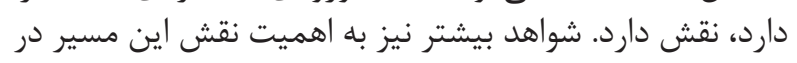

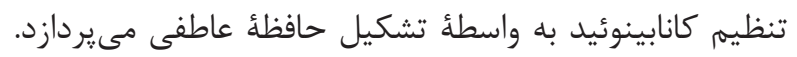

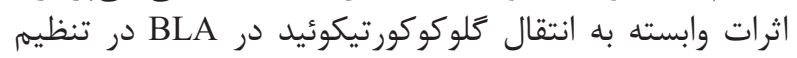

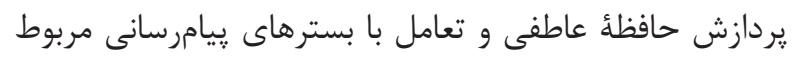

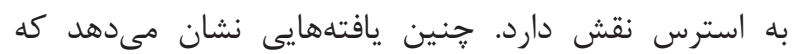

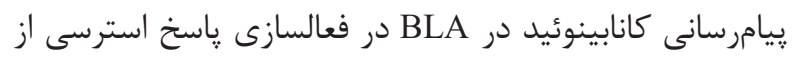

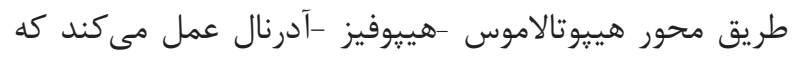

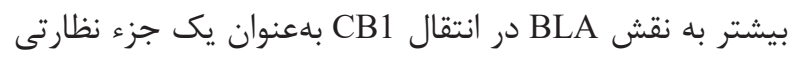

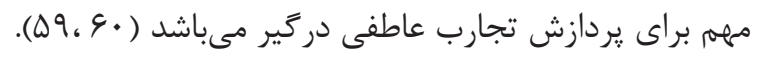

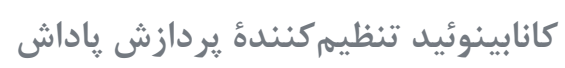

\section{كانابينوئيد و اعتياد}

اختلال در توانايى تشكيل حافظؤ مناسب و يادكيرى تطبيقى آن،

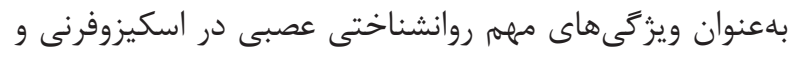

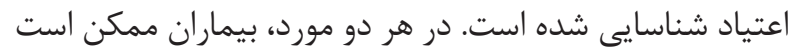

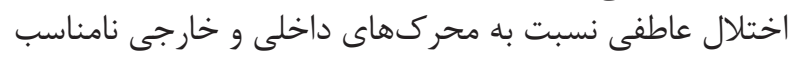

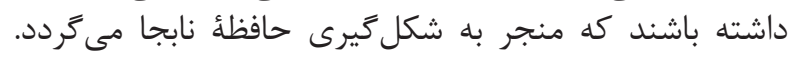

دريافت و همجنين فيبرهايى نيز به اين ناحيه مىفرستند. تحريك الكتريكى هسته هاى BAL مئى

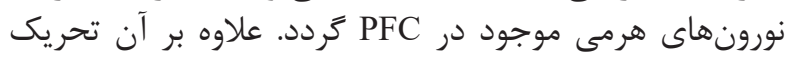

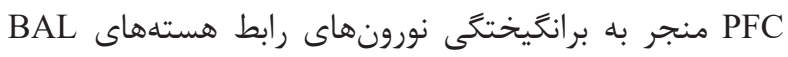

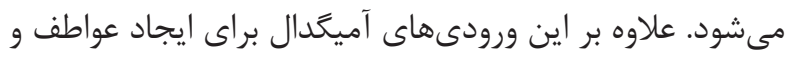

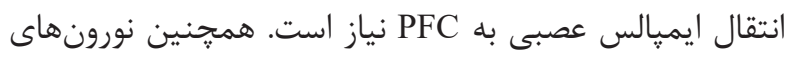

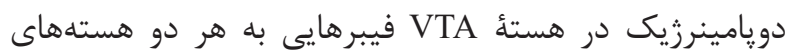

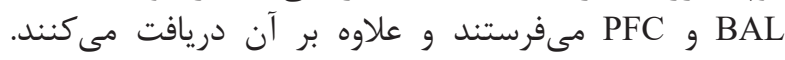

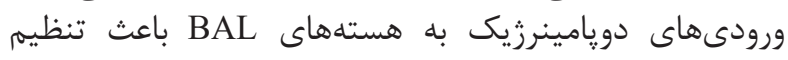

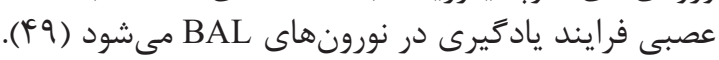

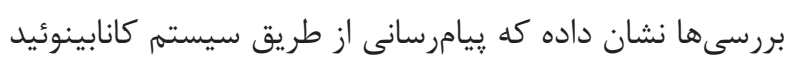

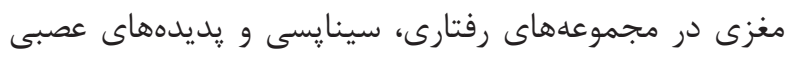

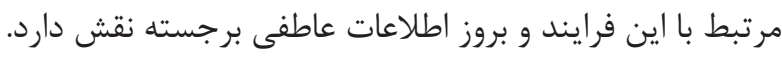

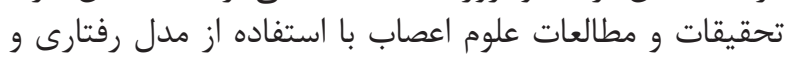

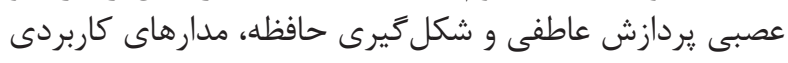

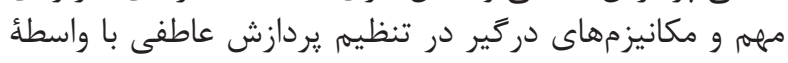

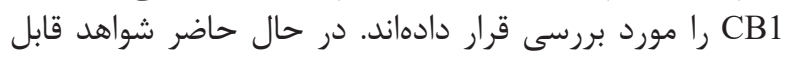

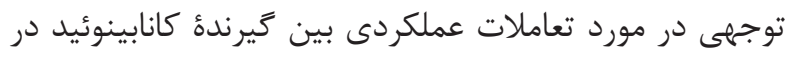

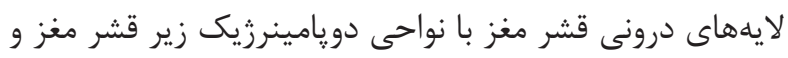
هستة BLA وجود دارد ( اله ، • (D).

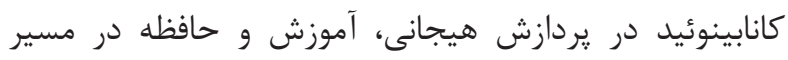

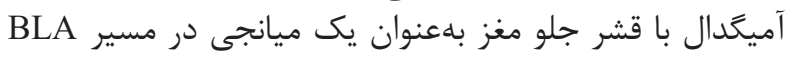

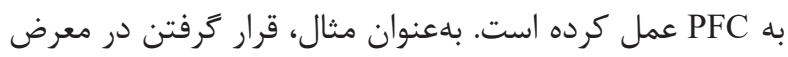

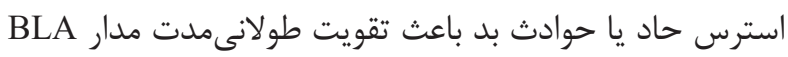

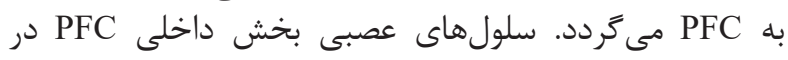

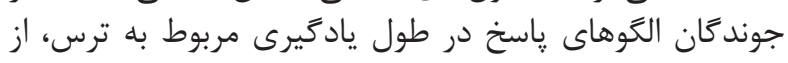

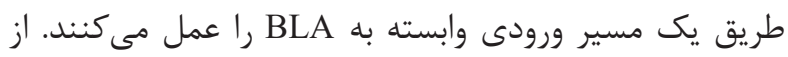

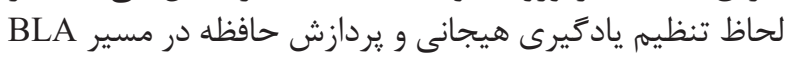

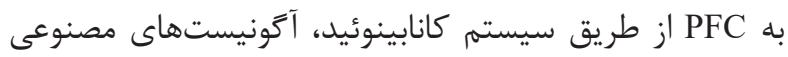

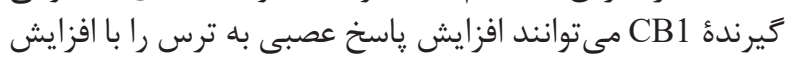

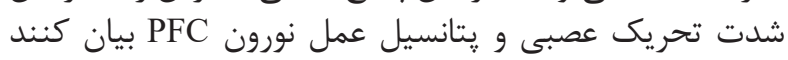

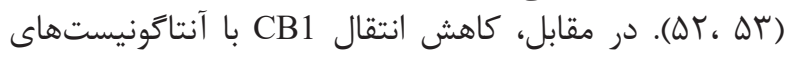

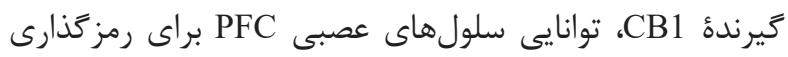

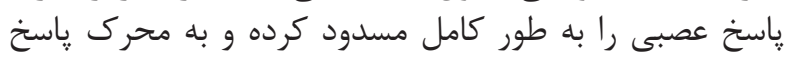

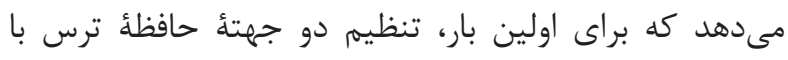

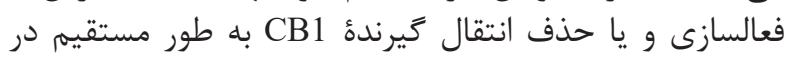

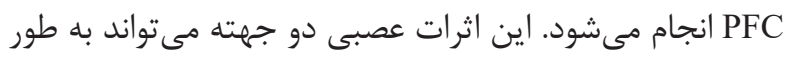

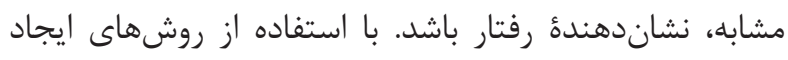

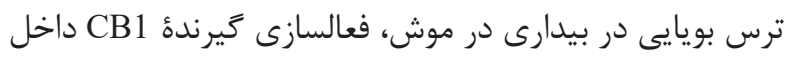

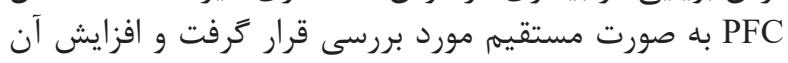

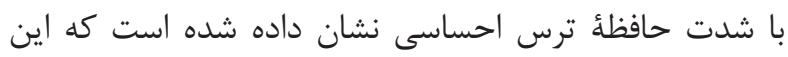

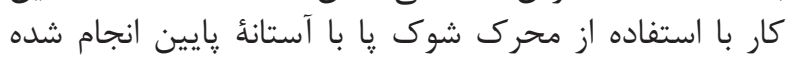

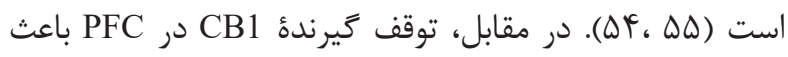

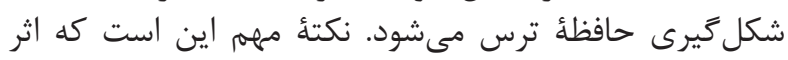

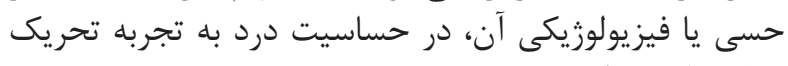
شوك پا مربوط نمى شود.

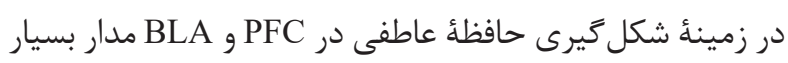
به هم يبيوستهاى از اتصالات صعودى و نزولى درلى نشان داده شده 


\section{كانابينوئيد و اسكيزوفرنى}

مقايسٔ بين كروههاى بيمار نشان مى دهد كه اثرات حاد آناد كانابيس

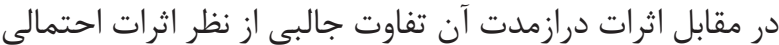

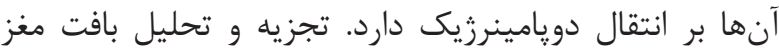

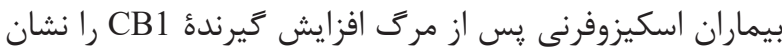

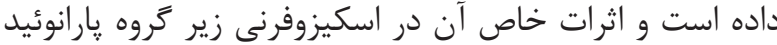

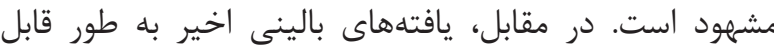

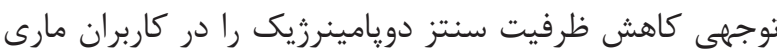

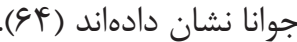

افراد مبتلا به اسكيزوفرنى ممكن است احساس نامناسبى به إنه

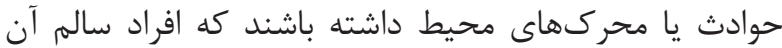

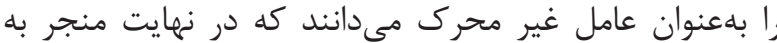

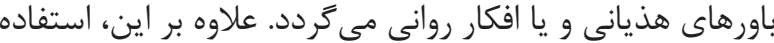

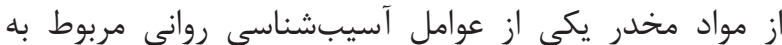

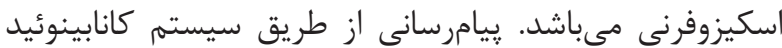

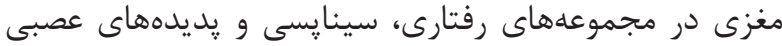

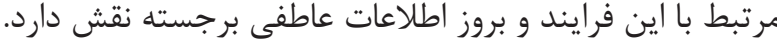

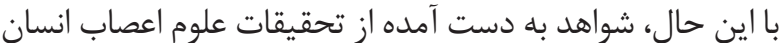

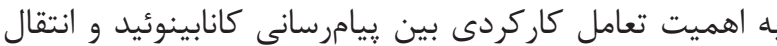

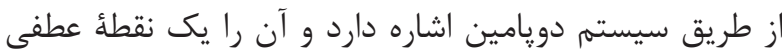

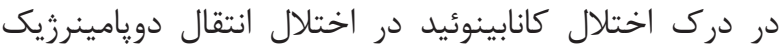

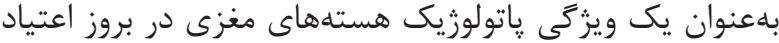

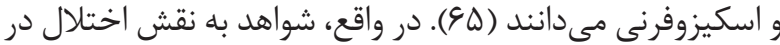

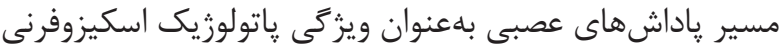

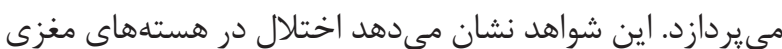

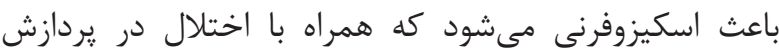

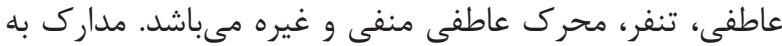

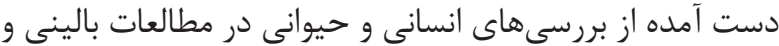

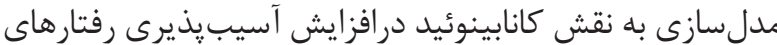

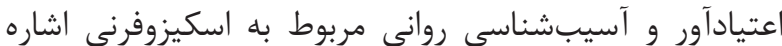

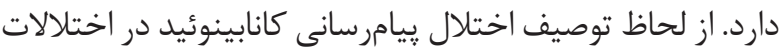

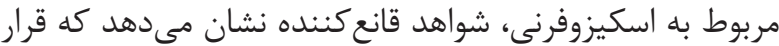

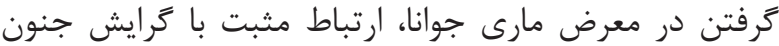

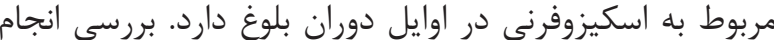

افراد وابسته به مواد، از جمله سوءمصرف مواد يا ساير اختلالات

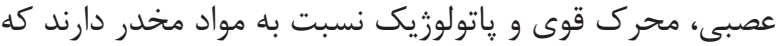

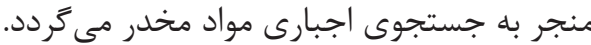

محركهاى مواد مخدر، يا ساير داروهاى مخدر و ويا به طور

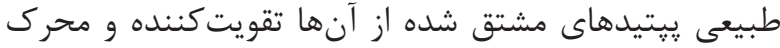

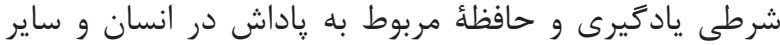

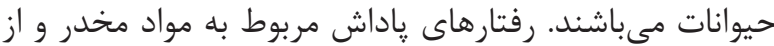

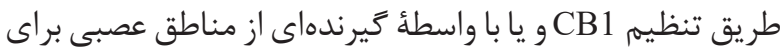

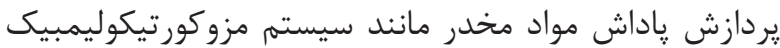

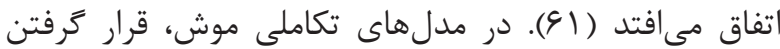

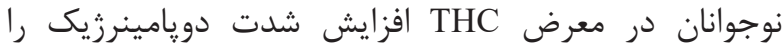

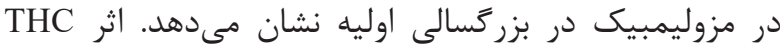

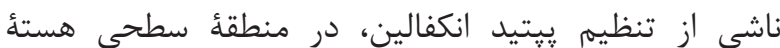

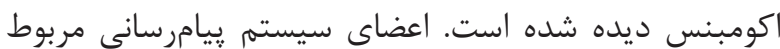

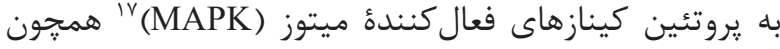

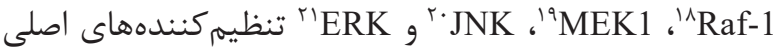

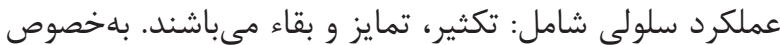

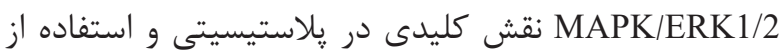

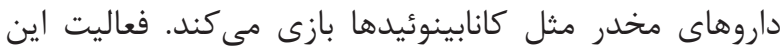

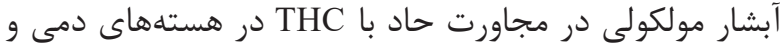

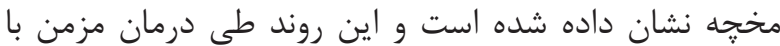

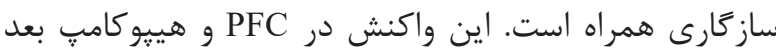

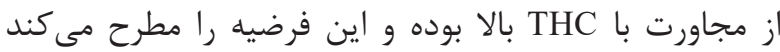

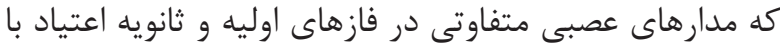

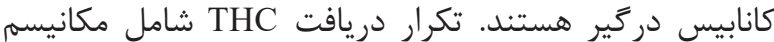

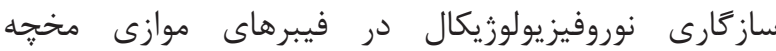

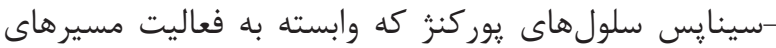

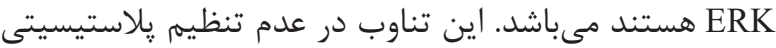

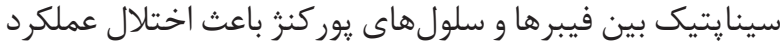

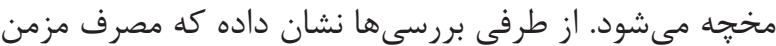

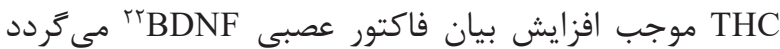

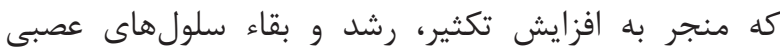
مى كَردد. علاوه بر آن مصرف مزمن

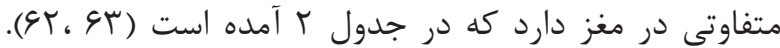

جدول r - مقايسٔ عملكردهاى مختلف مغز در برابر مصرف طولانىمدت THC در دو جنس مختلف (9D).

\begin{tabular}{|c|c|}
\hline مرد & زن \\
\hline افزايش فعاليت كيرندة CB1 در مادة خاكسترى مركزى & افزايش فعاليت CB1 در مادة خاكسترى مركزى \\
\hline افزايش فعاليت گيرندة CB1 در هييوكامٍٍ & افزايش فعاليت كيرندة CB1 در هييوكامبٍ \\
\hline كاهش فعاليت كيرندة CB1 در CA1 و جايروس دندانداى & افزايش فعاليت كيرندة CB1 در PFC \\
\hline كاهش حجم آميخدال راست & كاهش فعاليت NMAD و كلوتامات \\
\hline 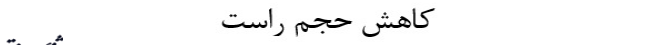 & كاهش توليد BDNF در هييوكامٍ \\
\hline
\end{tabular}

${ }^{17}$ Mitogen-activated protein kinase

${ }^{18}$ Ras proteins

${ }^{19}$ Mapk kinase
${ }^{20} \mathrm{C}$-jun $\mathrm{N}$-terminal kinase

${ }^{21}$ Extracellular signal-regulated kinases

${ }^{22}$ Brain derived neurotrophic factor 


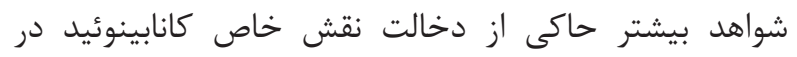

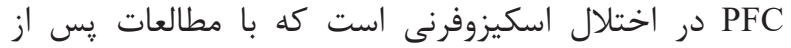

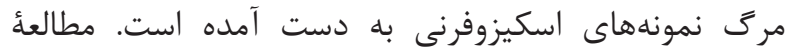

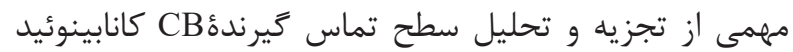

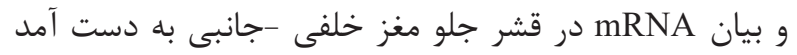

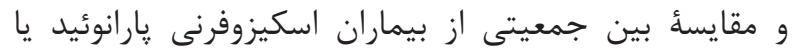

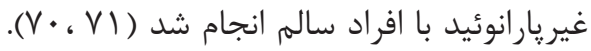
نتيجه كيرى

شواهد به دست آمده در سالهاى اخير وابستىى كانابينوئيدها

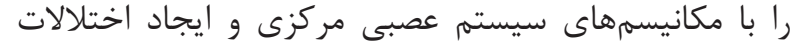

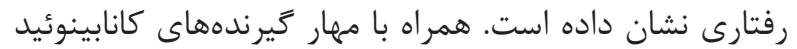

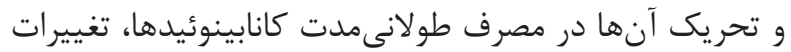

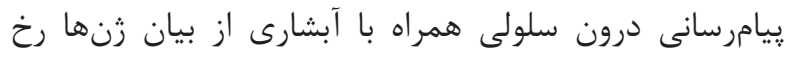

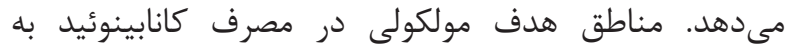

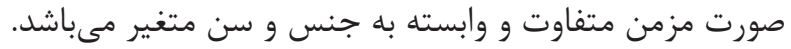

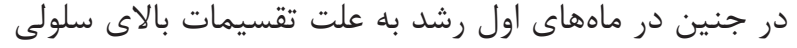

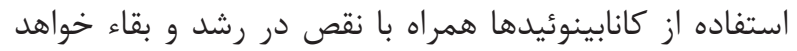

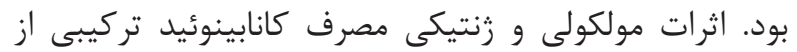

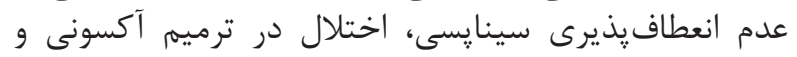

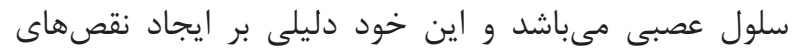

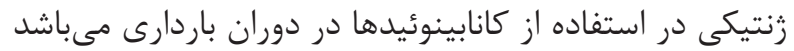

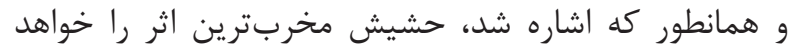

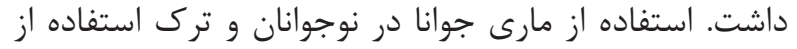

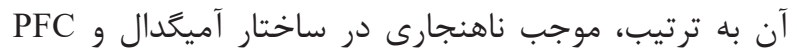

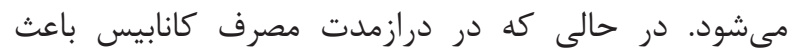

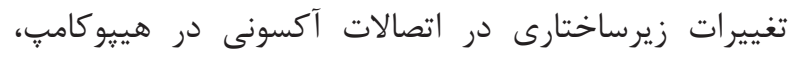
جسم بينه و الياف اتصالى مى زيردد (VT-VF).

1. Niswender CM, Conn PJ. Metabotropic glutamate receptors: physiology, pharmacology, and disease. Annu Rev Pharmacol Toxicol. 2010; 50: 295-322.

2. Wei D, Allsop S, Tye K, Piomelli DE. Ndocannabinoid signaling in the control of social behavior. Trends in Neurosciences. 2017; 40(7): 385-96.

3. Litim N, Morissette M, Paolo T. Metabotropic glutamate receptors as therapeutic targets in Parkinson's disease: an update from the last 5 years of research. Neuropharmacology. 2017; 115: 166-79.

4. Thomas J. Gould .Addiction and cognition. Addict Sci Clin Pract. 2010; 5(2): 4-14.

5. Laviolette SR. Grace AA. The roles of cannabinoid and dopamine receptor systems in neural emotional learning circuits: implications for schizophrenia and addiction. Cellular and Molecular Life Sciences CMLS. 2006; 63(14): 1597-613.

6. England L, Aagaard K, Bloch M, Conway K. Developmental toxicity of nicotine: a transdisciplinary

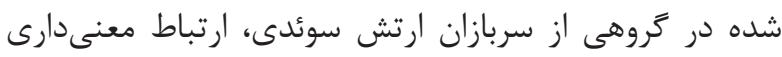

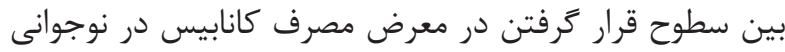
و ظهور اسكيزوفرنى در طول هار سال نشان داده است (91)

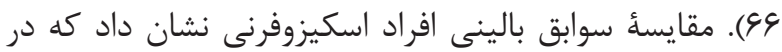

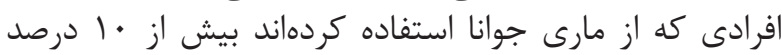

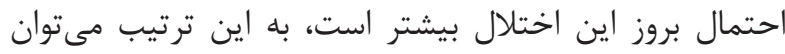

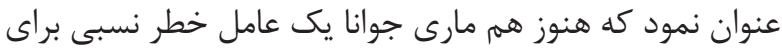

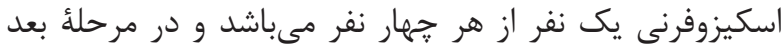

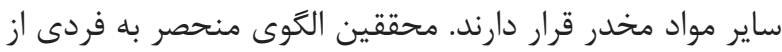

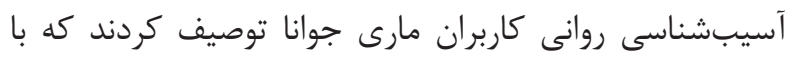

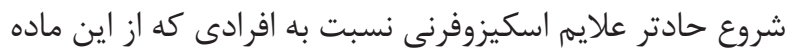
مخدر استفاده نكردهاند مشخص شاندر شدر است.

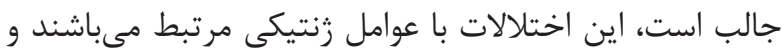

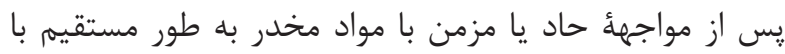

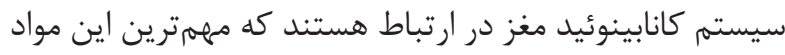

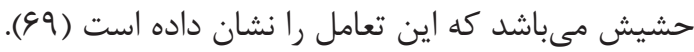

علاوه بر ارتباط مستقيم بين قرار گرفتن در معرض مارى جور جوانا

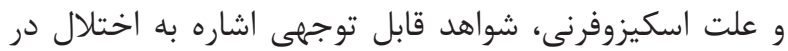

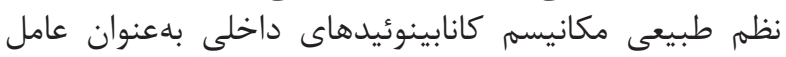

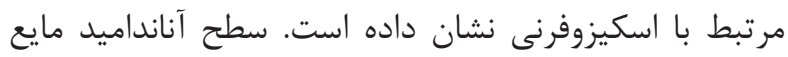

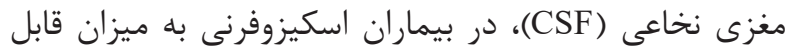

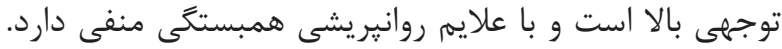

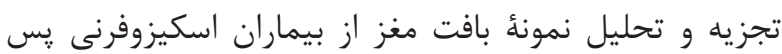

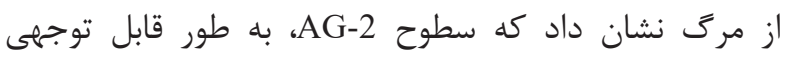

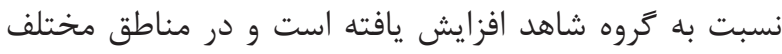

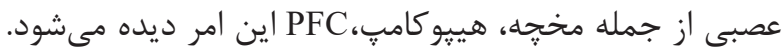

منابع

synthesis and implications for emerging tobacco products. Neuroscience and Biobehavioral Reviews. 2017; 72:176-89.

7. Prenderville JA, Kelly AM, Downer EJ. The role of cannabinoids in adult neurogenesis. Br J Pharmacol. 2015; 172(16): 3950-63.

8.LichtmanAH,MartinBR.Delta9-tetrahydrocannabinol impairs spatial memory through a cannabinoid receptor mechanism. Psychopharmacology. 1996; 126: 125-31.

9. Landeld PW, Cadwallader LB, Vinsant S. Quantitative changes in hippocampal structure following long-term exposure to delta 9- tetrahydrocannabinol: possible mediation by glucocorticoid systems. Brain Res. 1988; 443: 47-62.

10. Stella N, Piomelli D. Receptor-dependent formation of endogenous cannabinoids in cortical neurons. Eur J Pharmacol. 2001; 425: 189-96.

11. Pertwee, RG. Cannabinoid receptor ligands: clinical and neuropharmacological considerations, relevant to 


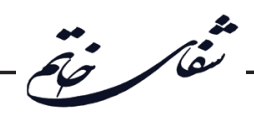

future drug discovery and development. Expert Opinion on Investigative Drugs. 2000; 9: 1553-71.

12. Maejima T, Hashimoto K, Yoshida T, Aiba A, Kano, M. Presynaptic inhibition caused by retrograde signal from metabotropic glutamate to cannabinoid receptors. Neuron. 2001; 31: 463-75.

13. Jerman JC, Brough SJ, Davis JB, Middlemiss DN, Smart D. The anandamide transport inhibitor AM404 is an agonist at the rat vanilloid receptor (VR1). British Journal of Pharmacology (Proceedings Supplement). 2000. 129: 73 .

14. Klumpers F, Denys D, Kenemans JL, Grillon C, van der Aart J, Baas JM. Testing the effects of Delta9-THC and D-cycloserine on extinction of conditioned fear in humans. Journal of Psychopharmacology. 2012; 26(4): 471-8.

15. Iversen L. Cannabis and the brain. Brain. 2003; 126: 1252-70.

16. Nava F, Carta G, Colombo G, Gessa GL. Effects of chronic Delta (9)-tetrahydrocannabinol treatment on hippocampal extracellular acetylcholine concentration and alternation performance in the T-maze. Neuropharmacology. 2001; 41: 392-9.

17. Pistis M, Porcu G, Melis M, Diana M, Gessa GL. Effects of cannabinoids on prefrontal neuronal responses to ventral tegmental area stimulation. Eur J Neurosci. 2001; 14: 96-102.

18. Lee I, Kesner RP. Differential roles of dorsal hippocampal subregions in spatial working memory with short versus intermediate delay. Behav Neurosci. 2003; 117: 1044-53.

19. Di S, Maxson M, Franco A, Tasker J. Glucocorticoids regulate glutamate and GABA synapse-specific retrograde transmission via divergent nongenomic signaling pathways. J Neurosci. 2009; 29: 393-401.

20. Bitencourt RM, Pamplona FA, Takahashi RN. Facilitation of contextual fear memory extinction and anti-anxiogenic effects of AM404 and cannabidiol in conditioned rats. Eur Neuropsychopharmacol. 2008; 18(12): 849-59.

21. Herkenham M, Lynn A, Johnson M, Melvin L. Characterization and localization of cannabinoid receptors in rat brain: a quantitative in vitro autoradiographic study. J Neurosci. 1991; 77(2): 563-83.

22. Schlicker E1, Kathmann M. Modulation of transmitter release via presynaptic cannabinoid receptors. Pharmacol Sci. 2001; 22(11): 565-72
23. Desarnaud F, Cadas H, Piomelli D. Anandamide amidohydrolase activity in rat brain microsomes. identification and partial characterization J Biol Chem. 1995; 270: 6030-5.

24. Pacher P, Mechoulam R. Is lipid signaling through cannabinoid 2 receptors part of a protective system? Prog Lipid Res. 2011; 50: 193-211.

25. Breivogel CS, Griffin G, Di Marzo V, Martin BR. Evidence for a new $G$ protein-coupled cannabinoid receptor in mouse brain. Mol Pharmacol. 2001; 60: 155-63.

26. Markowitsch HJ, Staniloiu A. "Amygdala in action: relaying biological and social significance to autobiographical memory". Neuropsychologia. 2011; 49(4): 718-33.

27. Papez JW. "A proposed mechanism of emotion. 1937’. J Neuropsychiatry Clin Neurosci. 1995; 7(1): 103-12.

28. https://en.wikipedia.org/wiki/Limbic_system.

29. Baxter MG, Murray EA. The amygdala and reward. Nat Rev Neurosci. 2002; 3: 563-73.

30. Finn DP, Beckett SR, Richardson D, Kendall DA, Marsden CA, Chapman V. Evidence for differential modulation of conditioned aversion and fear-conditioned analgesia by CB1 receptors. Eur J Neurosci. 2004; 20: 848-52.

31. Laviolette SR, Lipski WJ, Grace AAA subpopulation of neurons in the medial prefrontal cortex encodes emotional learning with burst and frequency codes through a dopamine D4 receptor-dependent basolateral amygdala input. J Neurosci. 2005; 25: 6066-75.

32. Lauzon NM, Bishop SF, Laviolette SR. Dopamine D1 versus D4 receptors differentially modulate the encoding of salient versus nonsalient emotional information in the medial prefrontal cortex. J Neurosci. 2009; 29: 4836-45.

33. Lee TT, Hill MN. Age of stress exposure modulates the immediate and sustained effects of repeated stress on corticolimbic cannabinoid CB1 receptor binding in male rats. Neuroscience. 2013; 26(249): 106-14.

34. Morin N, Jourdain VA, Morissette M, Gregoire L, Di Paolo T. Long-term treatment with 1-DOPA and an mGlu5 receptor antagonist prevents changes in brain basal ganglia dopamine receptors, their associated signaling proteins and neuropeptides in parkinsonian monkeys. Neuropharmacology. 2014; 79: 688-706.

35. Tan H, Ahmad T, Loureiro A, ZunderJ. The role 
of cannabinoid transmission in emotional memory formation: implications for addiction and schizophrenia. Front Psychiatry. 2014; 5: 73 . doi: 10.3389/ fpsyt.2014.00073.

36. Katona I, Rancz EA, Acsady L, Ledent C, Mackie $\mathrm{K}$, Hajos N, et al. Distribution of CB1 receptors in the amygdala and their role in the control of GABAergic transmission. J Neurosci. 2001; 21: 9506-18.

37. D'Souza DC, Pittman B, Perry E, Simen A. Preliminary evidence of cannabinoid effects on brainderived neurotrophic factor (BDNF) levels in humans. Psychopharmacology (Berl). 2009; 202: 569-78.

38. Hoffman AF, Lupica CR. Direct actions of cannabinoids on synaptic transmission in the nucleus accumbens: a comparison with opioids. J Neurophysiol. 2001; 85: 72-83.

39. Bechara A, vander Kooy D. Kappa receptors mediate the peripheral aversive effects of opiates. Pharmacol Biochem Behav. 1987; 28: 227-33.

40. Davis CM, Rice KC, Riley AL. Opiate-agonist Induced Taste Aversion Learning in the Fischer 344 and Lewis Inbred Rat Strains: Evidence for Differential Mu Opioid Receptor Activation. Pharmacol Biochem Behav. 2009; 93: 397-405.

41. Brown I, Cascio MG, Wahle KW, Smoum R, Mechoulam R, Ross RA, et al. Cannabinoid receptordependent and -independent anti-proliferative effects of omega-3 ethanolamides in androgen receptor-positive and -negative prostate cancer cell lines. Carcinogenesis. 2010; 31: 1584-91.

42. Gysling K, Wang RY. Morphine-inducedactivation of A10 dopamineneurons in therat. Brain Res. 1983; 277: 119-27. doi:10.1016/0006-8993(83)90913-7

43. Okuyama T, Kitamura T, Roy DS, Itohara SH, Tonegawa S. Ventral CA1 neurons store social memory. Science. 2016; 353: 1536-41.

44. Oleson EB, Cheer JF. Paradoxical effects of the endocannabinoiduptake inhibitor VDM11 onaccumbalneural encoding of reward predictivecues. Synapse. 2012; 66: 984-8.

45. Garcia-Barrantes PM, Cho HP, Niswender CM, Byers FW, Locuson CW, Blobaum AL, et al. Development of novel, CNS penetrant positive allosteric modulators for the metabotropic glutamate receptor subtype 1 (mGlu1), based on an N-(3-Chloro-4-(1,3- dioxoisoindolin-2-yl) phenyl)-3-methylfuran-2-carboxamide scaffold, that potentiate wild type and mutant mGlu1 receptors found in schizophrenics. J Med Chem. 2015; 58(20): 7959-71.
46. Gifford AN, Bruneus M, Gatley SJ, Volkow ND. Cannabinoid receptor-mediated inhibition of acetylcholine release from hippocampal and cortical synaptosomes. Br J Pharmacol. 2000; 131: 645-50.

47. Monory K, Polack M, Remus A, Lutz B, Korte M. Cannabinoid $\mathrm{CB} 1$ receptor calibrates excitatory synaptic balance in the mouse hippocampus. Journal of Neuroscience. 2015; 35(9): 3842-50.

48. Barati Dowom P, Darvishi M, Heidarbeigi $\mathrm{K}$. Neurological alterations in cognitive impairment. Shefaye Khatam. 2016; 4(4): 99-115.

49. witchell T, Brown S, Mackie K. Cannabinoids Inhibit $\mathrm{N}$ - and $\mathrm{P} / \mathrm{Q}$-type calcium channels in cultured rat hippocampal neurons. Journal of Neurophysiology. 1997; 78(1): 43-50.

50. Komaki H, Saadat F, Shahidi S, Sarihi A. The interactive role of $\mathrm{CB} 1$ receptors and L-type calcium channels in hippocampal long-term potentiation in rats. Brain Research Bulletin. 2017; 131: 168-75.

51. Loureiro M. Cannabinoid transmission in the hippocampus activates nucleus accumbens neurons and modulates reward and aversion-related emotional salience. Biological Psychiatry. 2016; 80(3): 216-25.

52. H Cadas E. di Tomaso D. Piomelli occurrence and biosynthesis of endogenous cannabinoid precursor, $\mathrm{N}$-arachidonoyl phosphatidylethanolamine, in rat brain. J Neurosci. 1997; 17: 1226-42.

53. Nomura DK, Long JZ, Niessen S, Hoover HS, Ng SW, Cravatt BF. Monoacylglycerol lipase regulates a fatty acid network that promotes cancer pathogenesis. Cell. 2010; 140(1): 49-61.

54. Aviello G, Borrelli F, Guida F, Romano B, Lewellyn $\mathrm{K}$, De Chiaro $\mathrm{M}$, et al. Ultrapotent effects of salvinorin A, a hallucinogenic compound from salvia divinorum, on LPS-stimulated murine macrophages and its antiinflammatory action in vivo. J Mol Med (Berl). 2011; 89: 891-902.

55. Booz GW. Cannabidiol as an emergent therapeutic strategy for lessening the impact of inflammation on oxidative stress. Free Radic Biol Med. 2011; 51: 1054-61.

56. Butovsky E, Juknat A, Goncharov I, Elbaz J, Eilam $\mathrm{R}$, Zangen $\mathrm{A}$, et al. In vivo up-regulation of brain-derived neurotrophic factor in specific brain areas by chronic exposure to Delta-tetrahydrocannabinol. J Neuroche. 2005; 93(4): 802-11.

57. López-Gallardo M, López-Rodríguez AB, Llorente- 


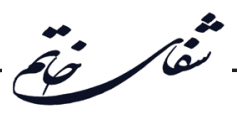

Berzal Á, Rotllant D, Mackie K, Armario A, et al.

Maternal deprivation and adolescent cannabinoid exposure impact hippocampal astrocytes, CB1 receptors and brain-derived neurotrophic factor in a sexually dimorphic fashion. Neuroscience. 2012; 204: 90-103.

58. Egertova M, Elphick MR. Localisation of cannabinoid receptors in the rat brain using antibodies to the intracellular C-terminal tail of CB. J Comp Neurol. 2000; 422: 159-71.

59. Gessa GL, Melis M, Muntoni AL, Diana M. Cannabinoids activate mesolimbic dopamine neurons by an action on cannabinoid CB1 receptors. Eur J Pharmacol. 1998; 341: 39-44.

60. Antoniadis EA, McDonald RJ. Discriminative fear conditioning to context expressed by multiple measures of fear in the rat. Behav Brain Res. 1999; 101: 1-13.

61. Azad SC, Eder M, Marsicano G, Lutz B, Zieglgansberger W, Rammes G. Activation of the cannabinoid receptor type 1 decreases glutamatergic and GABAergic synaptic transmission in the lateral amygdala of the mouse. Learn Mem. 2003; 10: 116-28.

62. Balleine BW, Dickenson A. Goal directed instrumental action: contingency and incentive learning and their cortical substrates. Neuropharmacology. 1998; 37: 407-19.

63. Devonshire IM, Mayhew JE, Overton PG. Cocaine preferentially enhances sensory processing in the upper layers of the primary sensory cortex. Neuroscience. 2007; 146(2): 841-51.

64. Friswell J, Phillips C, Holding J, Morgan CJ, Brandner B, Curran HV. Acute effects of opioids on memory functions of healthy men and women. Psychopharmacology (Berl). 2008; 198(2): 243-50.

65. Fratta W, Fattore L. Molecular mechanisms of cannabinoid addiction. Curr Opin Neurobiol .2013; 23(4): 487-92.
66. Galéra C, Bouvard MP, Messiah A, Fombonne E. Hyperactivity-inattention symptoms in childhood and substance use in adolescence: the youth gazel cohort. Drug Alcohol Depend. 2008; 94(1-3): 30-7.

67. Cacioppo JT, Amaral DG, Blanchard JJ, Cameron JL, Carter CS, Crews D, et al. Social neuroscience: progress and implications for mental health. Perspect Psychol Sci. 2016; 2: 99-123.

68. Goldstein RZ, Craig AD, Bechara A, Garavan H, Childress AR, Paulus MP. The neurocircuitry of impaired insight in drug addiction. Trends Cogn Sci. 2009; 13(9): 372-80.

69. Volk DW, Lewis DA. The role of endocannabinoid signaling in cortical inhibitory neuron dysfunction in schizophrenia. Biol Psychiatry. 2016; 79(7): 595-603.

70. Bangalore SS, Prasad KM, Montrose DM, Goradia DD, Diwadkar VA, Keshavan MS. Cannabis use and brain structural alterations in first episode schizophrenia: a region of interest, voxel based morphometric study. Schizophr Res. 2008; 99: 1-6.

71. Schneider M, Kasanetz F, Lynch DL, Friemel CM, Lassalle O, Hurst DP, et al. Enhanced functional activity of the cannabinoid type- 1 receptor mediates adolescent behavior. J Neurosci. 2015; 35(41): 13975-88.

72. Toro R, Leonard G, Lerner JV, Lerner RM, Perron M, Pike GB, et al. Prenatal exposure to maternal cigarette smoking and the adolescent cerebral cortex. Neuropsychopharmacology. 2008; 33(5): 1019-27.

73. Zalesky A, Solowij N, Yu“ cel M, Lubman DI, Takagi M, Harding IH, et al. Effect of long-term cannabis use on axonal fibre connectivity. Brain. 2012; 135: 2245-55.

74. Prenderville JA, Kelly ÁM, Downer EJ. The role of cannabinoids in adult neurogenesis. Br J Pharmacol. 2015; 172(16): 3950-63. 